\title{
Response Characteristics of the DeepCwind Floating Wind Turbine Moored by a Single-Point Mooring System
}

\author{
Yingyi Liu ${ }^{1, *}\left(\mathbb{D}\right.$, Shigeo Yoshida ${ }^{1}\left(\mathbb{D}\right.$, Hiroshi Yamamoto ${ }^{2}$, Akinori Toyofuku ${ }^{2}$, Guanghua He ${ }^{3}(\mathbb{D})$ \\ and Shunhan Yang 4 iD \\ 1 Research Institute for Applied Mechanics, Kyushu University, Kasuga 8168580, Japan; \\ yoshidas@riam.kyushu-u.ac.jp \\ 2 Interdisciplinary Graduate School of Engineering Sciences, Kyushu University, Kasuga 8168580, Japan; \\ yamamotoh@riam.kyushu-u.ac.jp (H.Y.); toyofukua@riam.kyushu-u.ac.jp (A.T.) \\ 3 School of Naval Architecture and Ocean Engineering, Harbin Institute of Technology, Weihai 264209, China; \\ ghhe@hitwh.edu.cn \\ 4 Department of Mechanics and Maritime Sciences, Chalmers University of Technology, \\ SE-412 96 Gothenburg, Sweden; shunhan.yang@chalmers.se \\ * Correspondence: liuyingyi@riam.kyushu-u.ac.jp; Tel.: +81-808-565-7934
}

Received: 19 October 2018; Accepted: 16 November 2018; Published: 20 November 2018

check for updates

\begin{abstract}
In recent years, the SPM (Single-Point Mooring) concept has been widely employed in several branches of the naval architecture and marine engineering field, such as FPSOs (Floating Production, Storage and Offloading units), offshore oil rigs, etc., but not yet popular in the offshore wind energy. To investigate the response characteristics of an SPM-moored FWT (Floating Wind Turbine), in the present work, we perform a numerical study on the DeepCwind semisubmersible wind turbine, using the state-of-the-art open-source tool FAST. The free-decay test results show that the SPM layout affects the natural periods of the wind turbine in rotational modes, as well as the mooring stiffness of the diagonal rotational and crossing rotational-translational terms, especially in relation to the yaw mode. Comparisons of the RAOs (Response Amplitude Operators) elucidate that the presence of wind influences significantly the sway, roll and yaw motions of the SPM layout. Finally, the weathervane test shows that an asymmetry exists in the free-yaw motion response when the semisubmersible wind turbine is moored by an SPM system.
\end{abstract}

Keywords: single-point mooring; semisubmersible; coupled dynamics

\section{Introduction}

OWE (Offshore Wind Energy) is a promising substitution of the traditional fossil fuels in the future. In recent years, the OWE technology is witnessing a booming development in which a variety of new conceptual designs have been realized [1-4]. The mooring system, as an essential part of the floating system for station keeping, is undergoing a quick update on the technology. One of the most recent developments is the concept of an FWT (Floating Wind Turbine) moored by an SPM (Single-Point Mooring) system [5-7]. Iijima et al. [5] designed a sample of an SPM-moored semisubmersible FWT and carried out a 1/100 scaled model test on the wave basin. Furthermore, it was observed that the FWT was capable of weathervaning. Koh et al. [6] performed a numerical analysis of a single-point moored TLS (Tension Leg Spar) and found that the TLS also could self-adjust its orientation to the inflow wind direction. Nihei et al. [7] carried out a tank model test of two different SPM bearing types and demonstrated that the combination usage of thrust bearing and aligning bearing perform better than using only the thrust bearing. From a technical point of view, the application of an SPM system enables the FWT to have free-yaw motions when the wind changes direction, which can be viewed as 
a passive yaw control system. In comparison to the active yaw control system normally installed in the turbine nacelle, the advantages of utilization of SPM can be generally summarized into the following two aspects:

- To reduce the cost of construction and the heavy weight due to the existence of nacelle yaw control system and the associated mechanical bearings and brakes at the tower top of wind turbine;

- To avoid the failure of a nacelle yaw system due to some sudden electricity-based accident or long-term corrosion caused by the humid salt-laden air in the sea circumstance.

SPM technology was firstly deployed in the offshore oil engineering, involving some FPSOs (Floating Production, Storage and Offloading units) and oil rigs [8-12]. FPSOs have been successfully installed in North Sea, Brazil, Mediterranean Sea, etc. for offshore oil exploitations and are moored in a variety of sea-depth regions from shallow water (around $30 \mathrm{~m}$ ) to ultra-deep water (2000-3000 m) [12]. The SPM systems applied in FPSOs are usually turret-mooring systems in which the presence of a large number of risers results in large-diameter turrets [13]. The weathervane capability of the SPM helps the self-adjusted FPSOs to be wave-aligned and therefore significantly reduces the wave impact on the FPSOs in harsh sea circumstances, due to the green water loadings, etc. [14]. In recent years, the SPM technology has also been introduced into WECs (Wave Energy Converters). E.g., Thomsen et al. [15,16] tested and discussed the applicability of using SPM systems in the floating WECs, and compared its merits and demerits with other mooring concepts in order to reach an optimization of the levelized cost of energy.

The main objective of the present research is to investigate the characteristic behaviors of a semisubmersible FWT moored by an SPM system. The present work aims to reveal in which way the SPM system affects the dynamic response of a semisubmersible-type FWT. A comparative study is undertaken in the meantime with the MPM (Multiple-Point Mooring) system to conduct the analysis and draw meaningful conclusions. The research is done with the aid of a well-proven reliable numerical simulation software FAST (Fatigue, Aerodynamics, Structures, and Turbulence). FAST is the NREL's (National Renewable Energy Laboratory's) primary open-source CAE (Computer Aided Engineering) tool for simulating the coupled aero-hydro-servo-elastic dynamic response of wind turbines. It is based on advanced engineering models which are derived from fundamental laws, but with appropriate simplifications and assumptions, and supplemented where applicable with computational solutions and test data [17]. In the present research, the latest FAST version 8.16 is used. This version has been developed based on the new modularization framework $[18,19]$ to improve the overall modularity. In addition, in accordance with FAST version 8.16, several useful utilities and tool boxes written in Python and Matlab are also used for the purposes of pre-processing and post-processing. In the subsequent parts, Section 2 presents the theories of the quasi-static and dynamic mooring modelling approaches for station keeping of the FWTs; Section 3 describes in detail about the models of floating structure, wind turbine and mooring layouts; Section 4 presents important computation results followed by analysis and discussions; the final conclusions are summarized in Section 5 .

\section{Mathematical Equations of the Coupled Dynamics Theory of a Moored FWT}

Equations of motion of a moored FWT can be derived based on the Kane's equation [20-22], taking into consideration of all nonlinearities and system's DOFs (Degrees of Freedom). Kane's equation is generally based on the principle that all generalized active forces and inertial forces acting on the complex system of the coupled rotor-nacelle assembly, the tower and the support platform are balanced. The kinetics equations for the support platform include contributions from the platform mass and inertia, gravity, hydro-restoring, hydrodynamics and the reaction forces of the mooring system, which can be written as

$$
F_{i}^{\text {Platform }}(q)=-\left(M_{i j}+A_{i j}\right) \ddot{q}_{j}-\int_{0}^{t} K_{i j}(t-\tau) \dot{q}_{j}(\tau) d \tau-C_{i j}^{\text {Hydrostatic }} q_{j}+F_{i}^{\text {Waves }}(q)+F_{i}^{\text {Lines }}(q)+\rho g V \delta_{i 3},
$$


where $M_{i j}, A_{i j}$ and $C_{i j}^{\text {Hydrostatic }}$ are the $(i, j)$ component of the platform mass matrix, impulsive hydrodynamic added-mass matrix and hydrostatic-restoring matrix, respectively; $q_{j}$ is the $j$ th DOF of the platform motions; $F_{i}^{\text {Waves }}$ represents the total excitation load on the support platform from incident waves; $K_{i j}$ is the $(i, j)$ component of the matrix known as the wave-radiation-retardation kernel or impulse-response functions; the last term on the right-hand side of Equation (1) represents the buoyancy force of the platform derived from Archimedes' principle, in which $\rho$ is the water density, $g$ is the gravity acceleration, $V$ is the displaced volume of water by the immersed part of the platform, $\delta_{i 3}$ is the $(i, 3)$ component of the Kronecker-Delta function; $F_{i}^{\text {Lines }}$ is the $i$ th component of the load on platform from all mooring lines.

It can be noted that the first three terms on the right-hand side of Equation (1) are all linear to the platform acceleration, velocity and displacement, respectively. $F_{i}^{\text {Waves }}$ and $F_{i}^{\text {Lines }}$ can be linear or nonlinear, depending on the requisite modelling complexity. For a generic problem, usually up to second-order wave forces are considered for the potential flow theory. It is sometimes supplemented by the Morison-strip theory in the case there exist slender braced members in the floating platform structure (which is also nonlinear). $F_{i}^{\text {Lines }}$ is usually modelled by a quasi-static method, e.g., the improved catenary theory [22], to calculate the tension force of every mooring line and them make a summation of them. When no portion of the line rests on the seabed, the analytical formulation of each line is as follows:

$$
\begin{gathered}
x_{F}\left(F_{H}, F_{V}\right)=\frac{F_{H}}{w}\left\{\ln \left[\frac{F_{V}}{F_{H}}+\sqrt{1+\left(\frac{F_{V}}{F_{H}}\right)^{2}}\right]-\ln \left[\frac{F_{V}-w L}{F_{H}}+\sqrt{1+\left(\frac{F_{V}-w L}{F_{H}}\right)^{2}}\right]\right\}+\frac{F_{H} L}{E A}, \\
z_{F}\left(F_{H}, F_{V}\right)=\frac{F_{H}}{w}\left[\sqrt{1+\left(\frac{F_{V}}{F_{H}}\right)^{2}}-\sqrt{1+\left(\frac{F_{V}-w L}{F_{H}}\right)^{2}}\right]+\frac{1}{E A}\left(F_{V} L-\frac{w L^{2}}{2}\right),
\end{gathered}
$$

where $x_{F}$ and $z_{F}$ are respectively the horizontal and vertical coordinates of the fairlead position relative to the anchor, $F_{H}$ and $F_{V}$ are the horizontal and vertical components of the effective tension in the mooring line at the fairlead, $w$ is the mass of the mooring line per unit length, $L$ is the total unstretched mooring line length, and $E A$ is the sectional stiffness of the mooring line. It is worth noting that Equations (2) and (3) should be solved iteratively in the local coordinate system via the Newton-Raphson method, etc.

When the environment conditions are severe or if the floating platform has large responses, high-fidelity mooring line models are recommended for the mooring analysis, especially for prediction of the mooring line loads. The existing high-fidelity models include FEA-based models and lumped-mass models. It appears that, although the FEA-based models can reach a good accuracy in prediction of the loads over a wide range of conditions, they are not computationally cost-effective [23]. In a lumped-mass model, the cable mass is discretized into point masses at every separate node by assigning it half of the combined mass of two adjacent cable segments. The complete equation of motion for each node $i$ is [23]

$$
\left(\boldsymbol{m}_{i}+\boldsymbol{a}_{i}\right) \ddot{\boldsymbol{r}}_{i}=\boldsymbol{T}_{i+(1 / 2)}-\boldsymbol{T}_{i-(1 / 2)}+\boldsymbol{B}_{i+(1 / 2)}-\boldsymbol{B}_{i-(1 / 2)}+\boldsymbol{W}_{i}+\boldsymbol{F}_{i}+\boldsymbol{D}_{p, i}+\boldsymbol{D}_{q, i}
$$

where $\boldsymbol{m}_{i}$ and $\boldsymbol{a}_{i}$ stands for the mass and added mass assigned at the node $i, \boldsymbol{T}$ and $\boldsymbol{B}$ stands for the internal stiffness and damping, $\boldsymbol{W}$ and $\boldsymbol{F}$ stands for the line net buoyancy and seabed contact, $\boldsymbol{D}_{p}$ and $D_{q}$ stands for the hydrodynamic drag force in the transverse and tangential directions, respectively. All of the above symbols in bold are $3 \times 3$ matrices.

Regarding the difference of the two mooring-line modelling methods, studies have been done previously by many other researchers. Thomsen et al. [15] stated that a quasi-static approach is not suitable to study the dynamic behavior of WECs when the mooring has significant nonlinearities, e.g., especially for synthetic ropes. It was later proved by their experimental testing of moorings for 
large floating wave energy converters in the wave basin at Aalborg University, in which a large $52 \%$ deviation was found by comparing with their measured line tension [24]. Hall et al. [25] concluded that mooring dynamics have an influence on platform motions only when those motions are large, but are always important to the prediction of mooring line loads. Wendt et al. [26] performed a thorough quantified comparison between the dynamic mooring and the quasi-static methods, showing that the lumped-mass method predicts smaller platform motions but larger mooring line tensions in the extensive presented results.

\section{Model Development of the Semisubmersible-Type FWTs}

\subsection{Floating Structure Model}

In the present research, the DeepCwind semi-submersible [27] is employed as the supporting platform or the floater, since it has been extensively tested in the U.S.-based OC4 project $[28,29]$, aiming at generating test data for use in validating floating offshore wind turbine modelling tools. The semisubmersible, as shown in Figure 1, is mainly composed by a central column and three outer offset columns, having a sound feature that heave plates (the base columns) are attaching to the bottom of the upper columns in order to prevent large heave motions of the platform. A host of slender bracings are also applied to connect between the columns and make the floating structure stiff. Geometrical specifications of the DeepCwind semi-submersible are listed in Table 1. More details can be found in Reference [27].

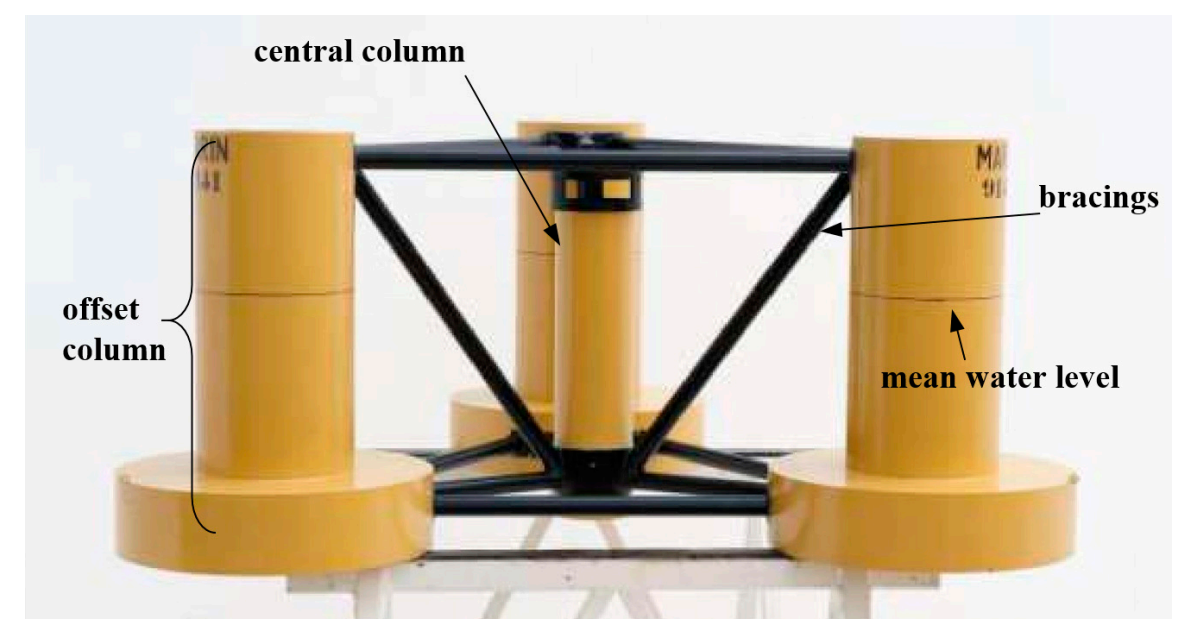

Figure 1. The 1/50 model scale semisubmersible in the DeepCwind tank tests $[27,30]$.

Hydrodynamics modelling for the supporting platform can be implemented in HydroDyn [31], which is a FAST built-in module. HydroDyn allows for multiple approaches in calculating the hydrodynamic loads on a structure. For the DeepCwind semisubmersible that consists of both large-diameter columns and slender bracing members, a general strategy is to apply the potential-flow theory solution to the former and the Morison strip-theory solution to the latter, similar to that have been done in Reference [32]. 
Table 1. Geometrical specifications of the DeepCwind semisubmersible platform.

\begin{tabular}{cc}
\hline Platform Properties & Value \\
\hline Platform draft & $20.0 \mathrm{~m}$ \\
Centerline spacing between offset columns & $50.0 \mathrm{~m}$ \\
Length of upper columns & $26.0 \mathrm{~m}$ \\
Length of base columns & $6.0 \mathrm{~m}$ \\
Diameter of main column & $6.5 \mathrm{~m}$ \\
Diameter of offset (upper) columns & $12.0 \mathrm{~m}$ \\
Diameter of base columns & $24.0 \mathrm{~m}$ \\
Diameter of pontoons and cross braces & $1.6 \mathrm{~m}$ \\
\hline
\end{tabular}

\subsection{Wind Turbine Model}

The NREL 5-MW baseline wind turbine is placed atop the DeepCwind semisubmersible. It has a three-bladed rotor with a diameter of $126 \mathrm{~m}$ and a cylindrical tower with a hub height of $90 \mathrm{~m}$. To control the baseline wind turbine, a variable-speed, variable blade-pitch-to-feather configuration is applied. Selected key properties for the wind speed and the mass distribution of the NREL 5-MW baseline wind turbine are listed in Table 2. More details can be found in Reference [22].

The aerodynamics of the baseline wind turbine, involving the aerodynamics of the rotor blades, the nacelle and the tower, can be modelled by the AeroDyn module of the FAST code. The structural deflections of the blades and the tower can be modelled by the ElastoDyn module. FAST can also be linked to a Bladed-style DLL (Dynamic Link Library), which is called by its ServoDyn module to control the wind turbine model in the real time.

Table 2. Selected properties of the NREL 5-MW baseline wind turbine.

\begin{tabular}{cc}
\hline Turbine Properties & Value \\
\hline Rotor configuration & Upwind, 3 Blades \\
Cut-in wind speed & $3 \mathrm{~m} / \mathrm{s}$ \\
Rated wind speed & $11.4 \mathrm{~m} / \mathrm{s}$ \\
Cut-out wind speed & $25 \mathrm{~m} / \mathrm{s}$ \\
Rotor mass & $110,000 \mathrm{~kg}$ \\
Nacelle mass & $240,000 \mathrm{~kg}$ \\
Tower mass & $347,460 \mathrm{~kg}$ \\
\hline
\end{tabular}

\subsection{Mooring System Models}

The station keeping of the platform is provided by three slack catenary chain moorings. In the multi-point mooring system, the fairleads of the mooring lines are located at the top of the base columns at a depth of $14.0 \mathrm{~m}$ below the mean sea level and at a radius of $40.87 \mathrm{~m}$ from the platform centerline. In the single-point mooring system, the mooring lines are allocated to a single fairlead which is located at the bottom center of the central column at a depth of $20.0 \mathrm{~m}$ below the mean sea level. To keep the same vertical line configuration for the fairness of comparison, in the SPM case, the water depth is adjusted to be also $6 \mathrm{~m}$ larger than the original water depth, i.e., $206 \mathrm{~m}$, which almost has no effect on the wave dynamics since the water depth exceeds half wave lengths of most sea waves. In such configurations, all the lines can have the same line length and geometrical shape. The only factor that differs in affecting the system's behavior will then be the collection of the separated fairleads. Sketch of the two mooring system configurations from both the top view and side view is shown in Figure 2. Details of the multi-point mooring system and the single-point mooring system are listed in Tables 3-5. 


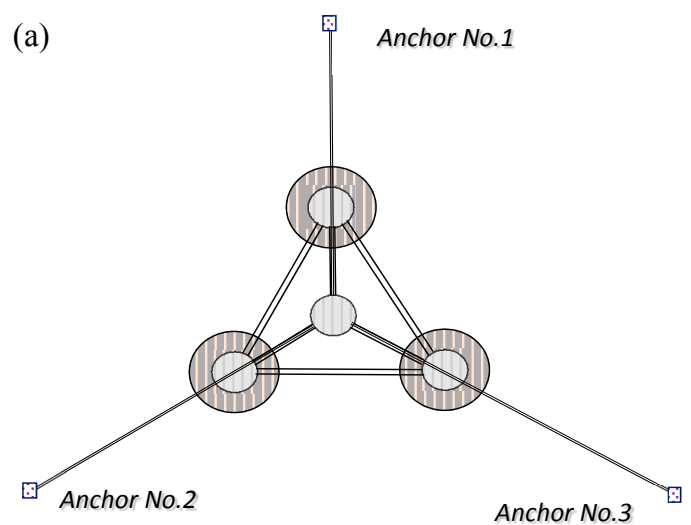

(b)
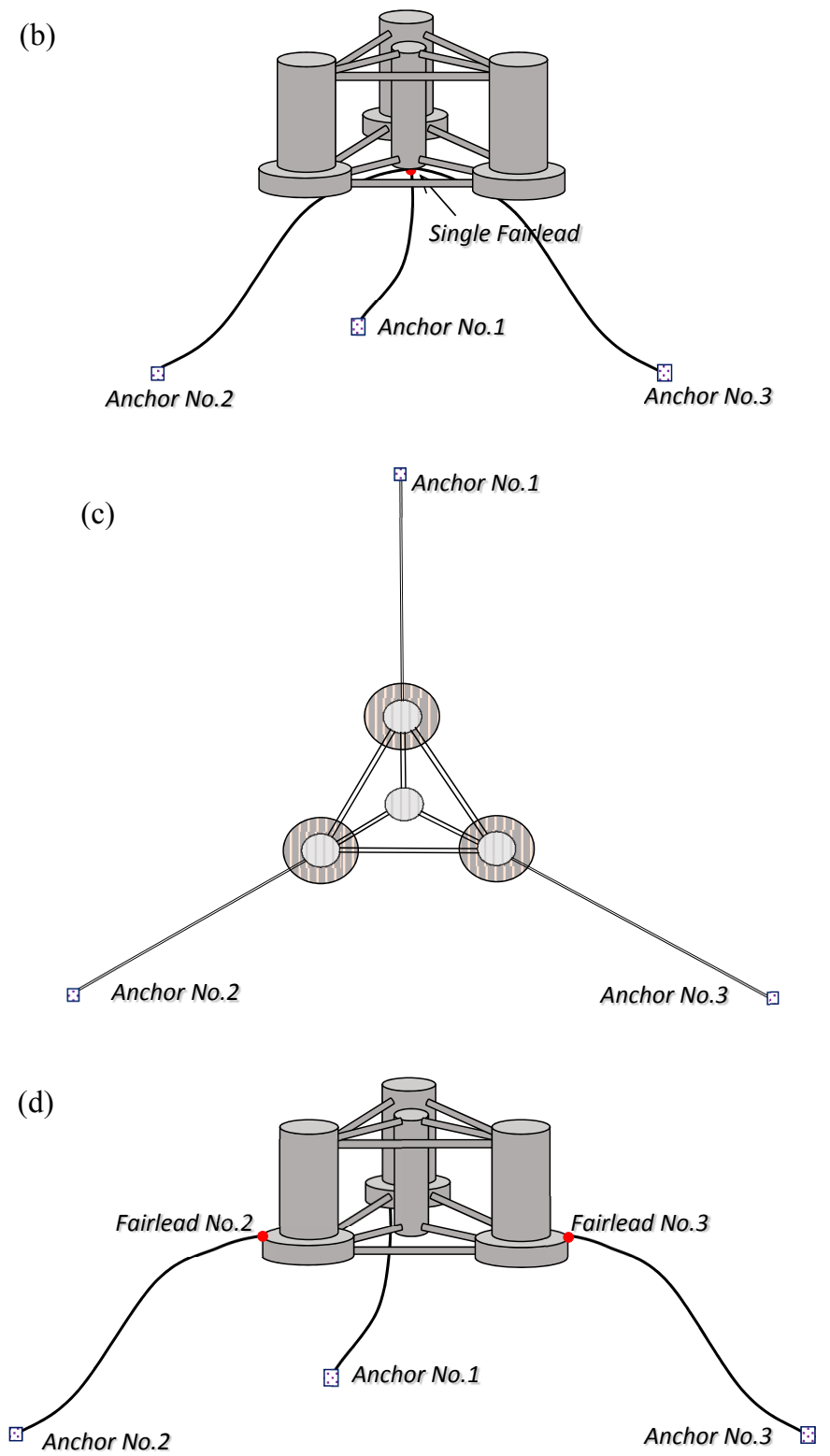

Figure 2. Sketch of the two mooring system configurations: (a) top view of the SPM (Single-Point Mooring) layout; (b) side view of the SPM layout; (c) top view of the MPM (Multiple-Point Mooring) layout; (d) side view of the MPM layout. Note that the aspect ratio of the floating platform is enlarged for the better illustration. 
Table 3. Global coordinates of the anchor points and the fairlead points in the single-point mooring system and the multi-point mooring system; SPM: Single-Point Mooring, MPM: Multiple-Point Mooring.

\begin{tabular}{cccccccc}
\hline \multirow{2}{*}{ Node Number } & \multirow{2}{*}{ Node Type } & \multicolumn{3}{c}{ SPM Node Coordinates } & \multicolumn{3}{c}{ MPM Node Coordinates } \\
\cline { 3 - 8 } & & $\mathbf{X}$ & $\mathbf{Y}$ & $\mathbf{Z}$ & $\mathbf{X}$ & $\mathbf{Y}$ & $\mathbf{Z}$ \\
\hline 1 & Fix & 398.366 & 689.99 & -206.00 & 418.800 & 725.38 & -200.00 \\
2 & Fix & -796.732 & 0.00 & -206.00 & -837.600 & 0.00 & -200.00 \\
3 & Fix & 398.366 & -689.99 & -206.00 & 418.800 & -725.38 & -200.00 \\
4 & Vessel & 0.00 & 0.00 & -20.00 & 20.434 & 35.393 & -14.00 \\
5 & Vessel & - & - & - & -40.868 & 0.00 & -14.00 \\
6 & Vessel & - & - & - & 20.434 & -35.393 & -14.00 \\
\hline
\end{tabular}

Note: in the node type, "Fix" means the anchors, and "Vessel" means the fairleads.

Table 4. The composition of line nodes in two different configurations.

\begin{tabular}{ccccc}
\hline \multirow{2}{*}{ Line Number } & \multicolumn{2}{c}{ SPM Configuration } & \multicolumn{2}{c}{ MPM Configuration } \\
\cline { 2 - 5 } & Anchor Node & Fairlead Node & Anchor Node & Fairlead Node \\
\hline I & 1 & 4 & 1 & 4 \\
II & 2 & 4 & 2 & 5 \\
III & 3 & 4 & 3 & 6 \\
\hline
\end{tabular}

Table 5. Major line-properties of the two mooring system configurations.

\begin{tabular}{cc}
\hline Line Properties & Value \\
\hline Mooring Line Diameter & $0.0766 \mathrm{~m}$ \\
Equivalent Line Mass Density in Air & $113.35 \mathrm{~kg} / \mathrm{m}$ \\
Equivalent Line Mass Density in Water & $108.63 \mathrm{~kg} / \mathrm{m}$ \\
Equivalent Mooring Line Extensional Stiffness & $753.6 \times 10^{6} \mathrm{~N}$ \\
Seabed Drag Coefficient & 1.0 \\
Unstretched Mooring Line Length & $835.5 \mathrm{~m}$ \\
\hline
\end{tabular}

The two mooring systems are modelled by the MAP++ and MoorDyn, which are both open-source available. MAP++ is a library designed for the purpose of an MSQS (Multi-Segmented, Quasi-Static) mooring line. The MSQS model is developed based on an extension of conventional single line static solutions [33,34]. MoorDyn is based on a lumped-mass approach which is capable of modelling the mooring dynamics. Both of the two models consider mooring stiffness, inertia, weight, buoyancy and seabed friction. In addition, MoorDyn considers additionally the line damping and the line drag force, which have not yet been modelled in MAP++. The two softs have been intended to support the modelling of marine renewable energy systems, e.g., floating offshore wind turbines, wave energy converters, ocean current turbines, etc. By adhering to the NREL's new modularization framework $[19,35]$, they are seamlessly integrated into the FAST software via a dynamically link mechanism.

\section{Results and Discussion}

Numerical simulations are performed extensively as displayed below to study the different behaviors of the floating wind turbine applying the MPM and the SPM systems. Discussions are given in detail thereafter following the analysis of the simulation results.

\subsection{Free-Decay Test}

Free-decay tests for the surge, sway, heave, roll, pitch and yaw DOFs are performed using both the MAP++ and the MoorDyn packages. Details of the simulation settings are shown in Table 6 . The LCs (Load Cases) considered here correspond to LCs 1.3a d in the OC4, Phase II Project. All the 
platform and mooring DOFs are enabled while the generator DOFs are disabled. Computations for the inflow wind velocities and aerodynamic loads are disabled, while computations for the hydrodynamic loads, the structural dynamics and the mooring system are enabled. This is because, although there is no wind and wave, the motion of floating wind turbine generates radiated waves that can induce hydrodynamic loads on the platform and the mooring lines.

Table 6. Properties of load cases in the free-decay test; DOFs: Degrees of Freedom.

\begin{tabular}{|c|c|c|c|c|c|c|}
\hline Load Case & Description & $\begin{array}{c}\text { Initial } \\
\text { Conditions }\end{array}$ & $\begin{array}{l}\text { Enabled } \\
\text { DOFs }\end{array}$ & $\begin{array}{l}\text { Simulation } \\
\text { Length }\end{array}$ & $\begin{array}{c}\text { Wind } \\
\text { Condition }\end{array}$ & $\begin{array}{c}\text { Wave } \\
\text { Condition }\end{array}$ \\
\hline I & $\begin{array}{l}\text { Free decay, } \\
\text { surge }\end{array}$ & Surge $=+22 \mathrm{~m}$ & $\begin{array}{l}\text { Platform and } \\
\text { moorings }\end{array}$ & $20 \mathrm{~min}$ & No wind & Still water \\
\hline II & $\begin{array}{l}\text { Free decay, } \\
\text { sway }\end{array}$ & Sway $=+22 \mathrm{~m}$ & $\begin{array}{l}\text { Platform and } \\
\text { moorings }\end{array}$ & $20 \mathrm{~min}$ & No wind & Still water \\
\hline III & $\begin{array}{l}\text { Free decay, } \\
\text { heave }\end{array}$ & Heave $=+6 \mathrm{~m}$ & $\begin{array}{l}\text { Platform and } \\
\text { moorings }\end{array}$ & $5 \mathrm{~min}$ & No wind & Still water \\
\hline IV & $\begin{array}{c}\text { Free decay, } \\
\text { roll }\end{array}$ & Roll $=+8$ deg & $\begin{array}{l}\text { Platform and } \\
\text { moorings }\end{array}$ & $5 \mathrm{~min}$ & No wind & Still water \\
\hline $\mathrm{V}$ & $\begin{array}{l}\text { Free decay, } \\
\text { pitch }\end{array}$ & Pitch $=+8$ deg & $\begin{array}{l}\text { Platform and } \\
\text { moorings }\end{array}$ & $5 \mathrm{~min}$ & No wind & Still water \\
\hline VI & $\begin{array}{c}\text { Free decay, } \\
\text { yaw }\end{array}$ & Yaw $=+8 \mathrm{deg}$ & $\begin{array}{l}\text { Platform and } \\
\text { moorings }\end{array}$ & $15 \mathrm{~min}$ & No wind & Still water \\
\hline
\end{tabular}

In the free-decay test, the floating system was offset an initial displacement and allowed to damp out until reaching the equilibrium position. From the time-series of the simulation results, as shown in Figure 3 , it is found that while the natural periods of the translational modes (surge, sway and heave) do not change due to the SPM layout, the natural periods of the rotational modes (roll, pitch and yaw) are elongated noticeably. This is because the diagonal rotational terms of the mooring stiffness matrix are decreased in the SPM layout, as shown in Equation (6), leading to the slower of the rotational natural periods (natural periods are inversely proportional to the square root of the corresponding mooring stiffness). Furthermore, natural periods and damping ratios of those computed by MoorDyn are slightly larger than those of MAP++, especially for the surge and the sway modes. This is proved clearly by the analysis results of the natural periods and the damping ratios of all the free-decay time-series data (see Table 7). The reason is that MoorDyn includes the effect of line damping and line drag force while MAP++ has not yet considered it. However, the damping ratios in all DOFs except that of yaw maintain almost the same values with no effect from the SPM layout. Moreover, in the yaw decay test, the yaw displacement does not return to the equilibrium position with the increase of time. This means that the platform does not possess any mooring restoring stiffness in the yaw DOF of the SPM turbine, which coincides with our expectation for the SPM layout.

Table 7. Analysis results of the free-decay test.

\begin{tabular}{ccccccccccc}
\hline \multirow{2}{*}{ Terms } & \multirow{2}{*}{ Surge } & \multirow{2}{*}{ Sway } & \multirow{2}{*}{ Heave } & \multicolumn{2}{c}{ Roll } & \multicolumn{2}{c}{ Pitch } & \multicolumn{2}{c}{ Yaw } \\
\cline { 5 - 10 } & & & & & SPM & MPM & SPM & MPM & SPM & MPM \\
\hline \multirow{2}{*}{ MAP++ } & Natural period (s) & 112.3 & 112.5 & 17.4 & 26.3 & 25.6 & 26.2 & 25.6 & Infinite & 79.0 \\
\multirow{3}{*}{ MoorDyn } & Damping ratio (\%) & 4.32 & 4.26 & 3.65 & 3.12 & 3.20 & 3.13 & 3.30 & 0.00 & 1.83 \\
& Natural period (s) & 113.4 & 113.5 & 17.4 & 26.3 & 25.8 & 26.2 & 25.8 & Infinite & 79.3 \\
& Damping ratio (\%) & 4.87 & 4.84 & 3.65 & 3.12 & 3.34 & 3.13 & 3.35 & 0.00 & 2.20 \\
\hline
\end{tabular}


(a)

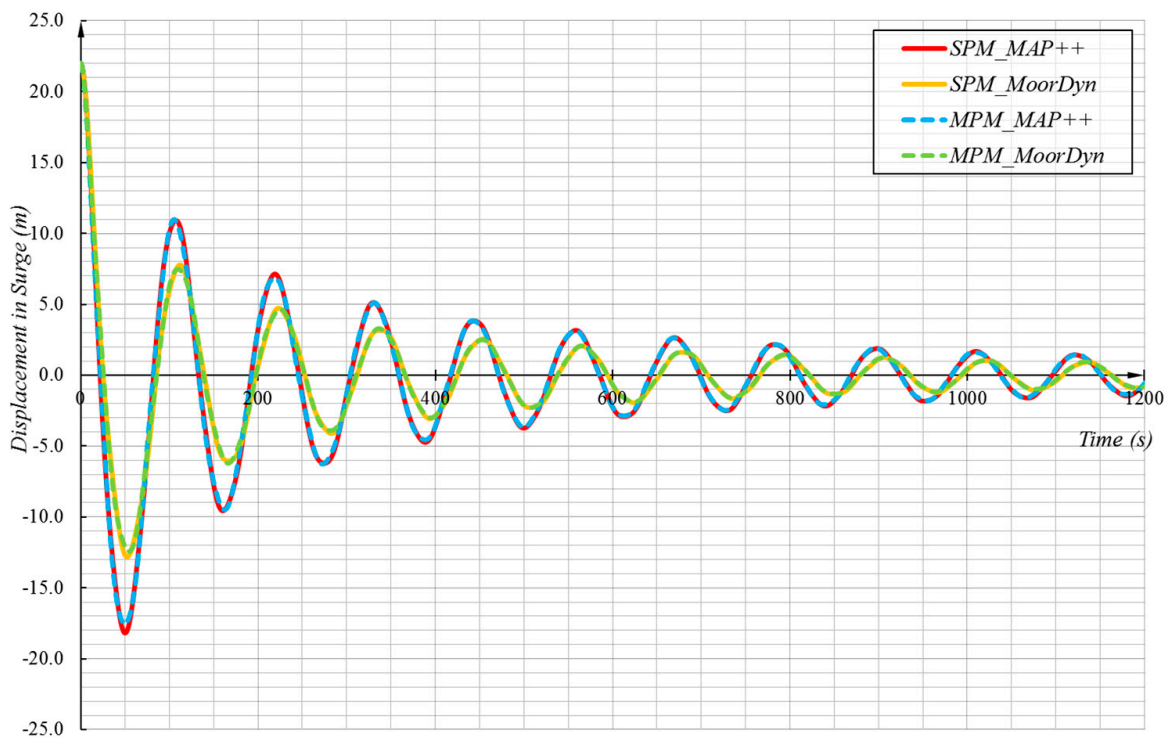

(b)

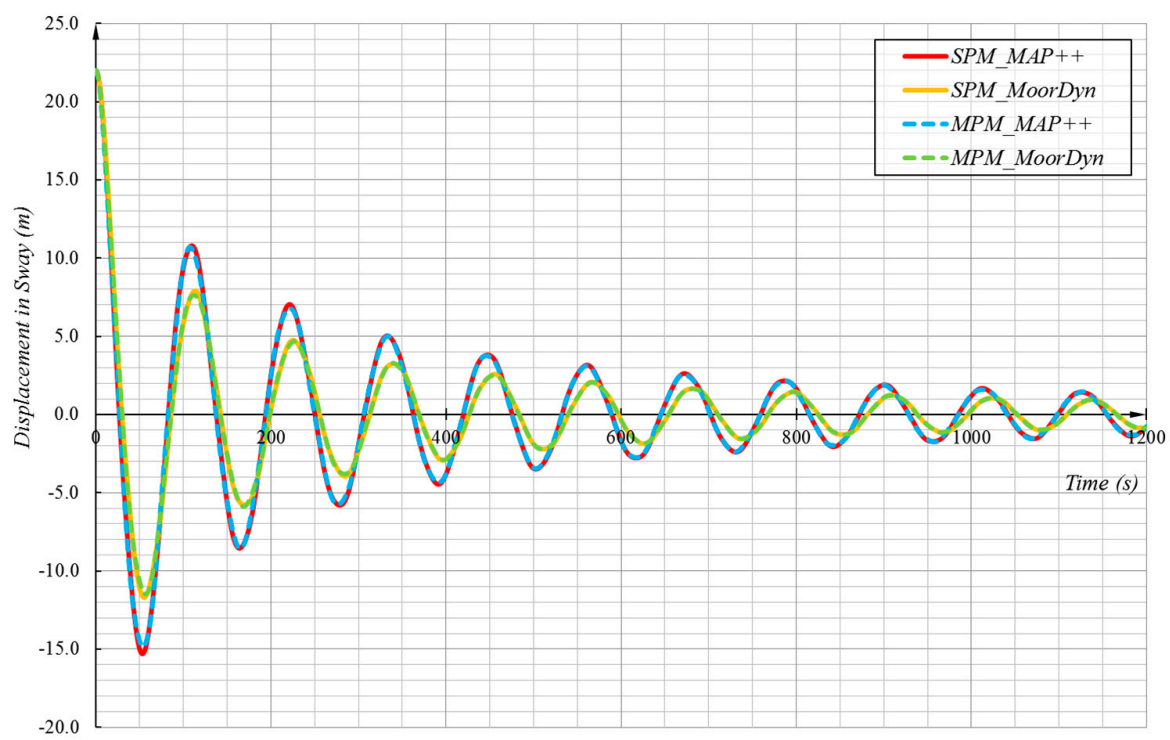

(c)

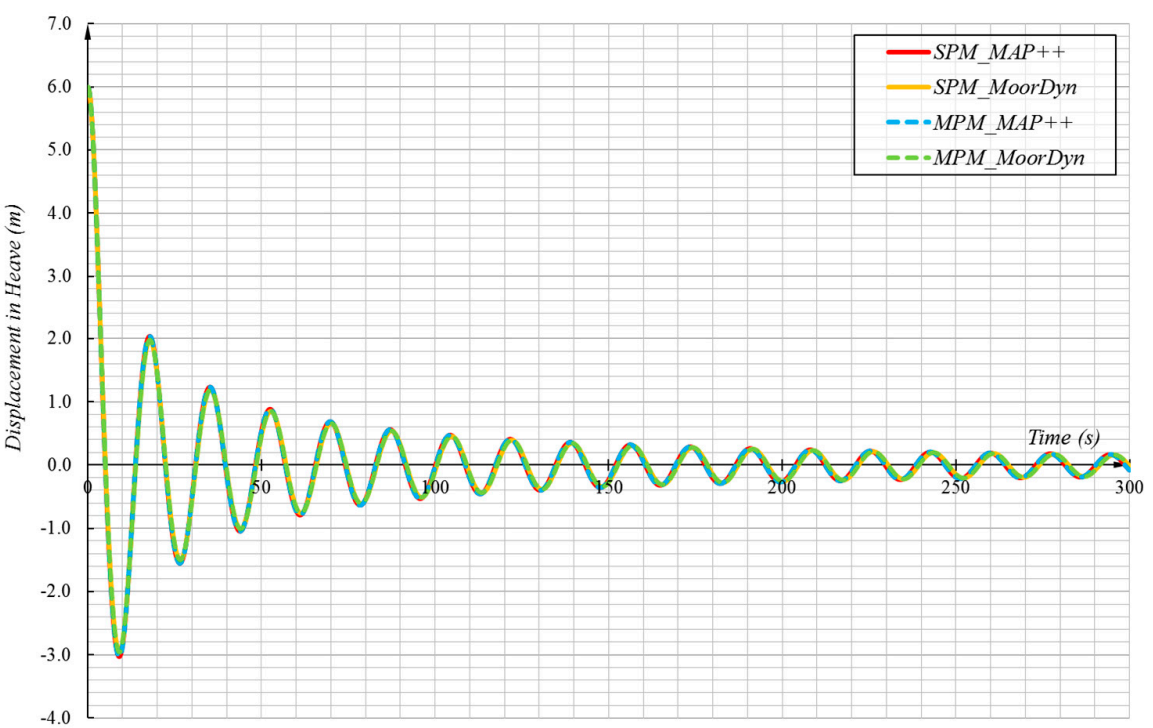

Figure 3. Cont. 
(d)

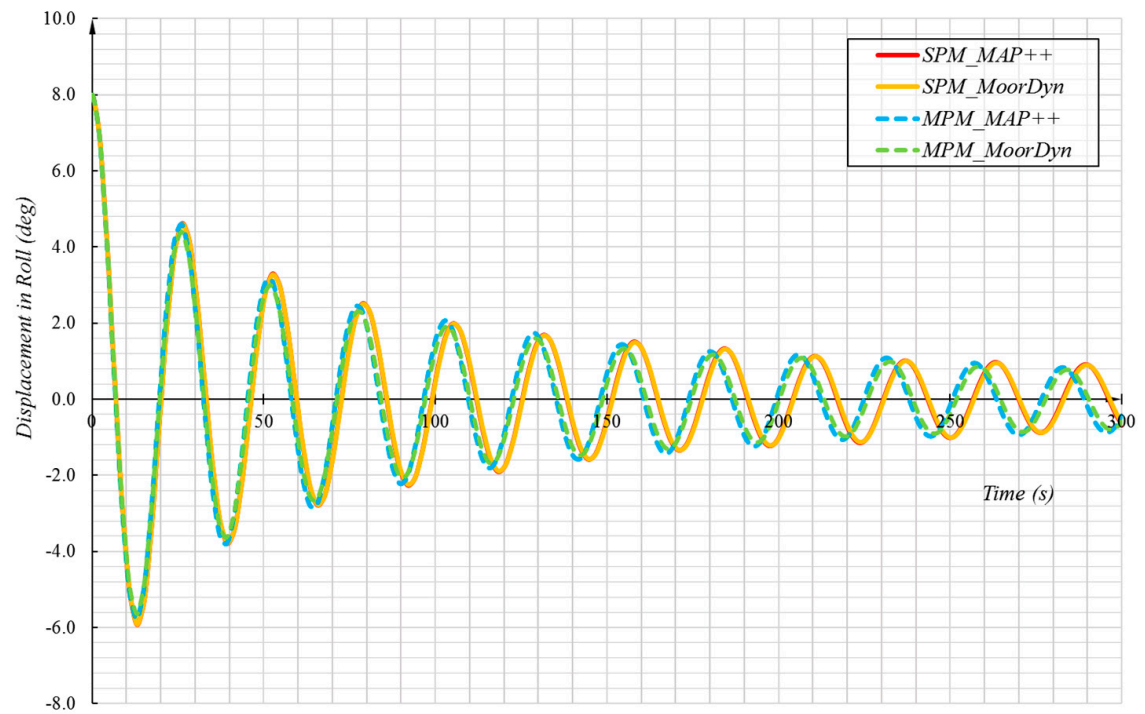

(e)

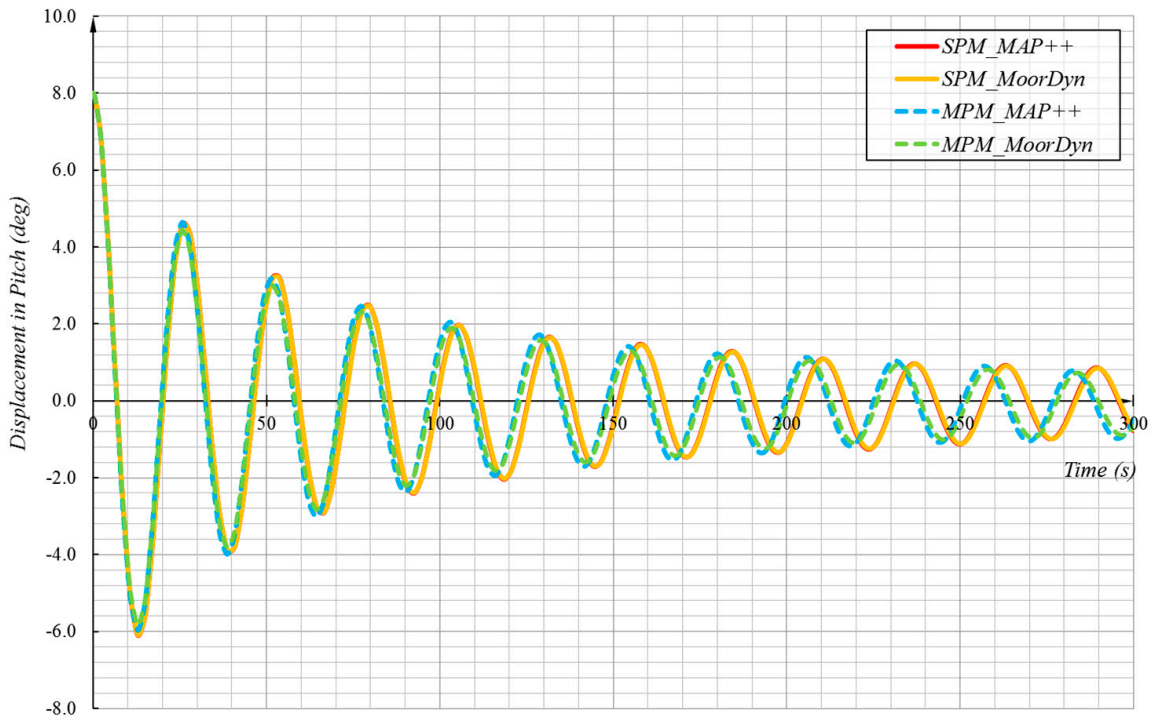

(f)

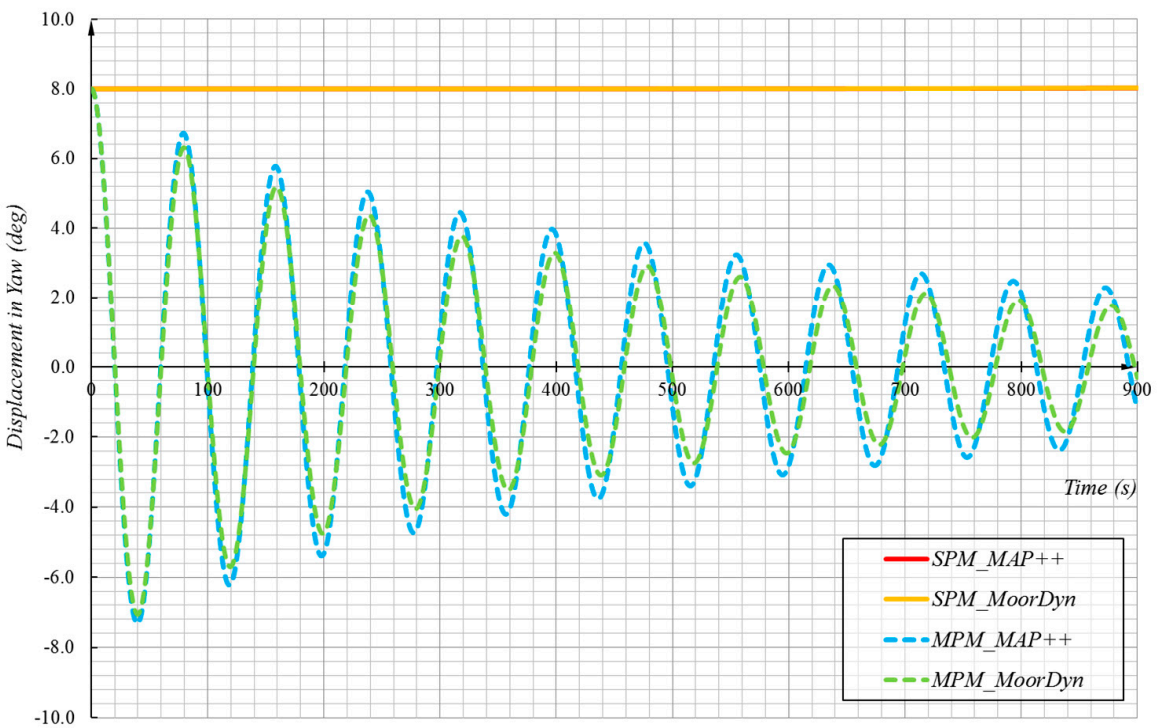

Figure 3. Time histories of the free-decay test: (a) surge decay; (b) sway decay; (c) heave decay; (d) roll decay; (e) pitch decay; (f) yaw decay; SPM: Single-Point Mooring, MPM: Multiple-Point Mooring. 


\subsection{Force-Displacement Relationship}

To find the difference of the inherent nature between the MPM and the SPM mooring layouts, their force-displacement relationships for the DeepCwind semisubmersible wind turbine are further calculated based on an open-source Python wrapper of the mooring solver MAP++ package [33]. The Python wrapper is called later by our in-house routine developed for this purpose (see the part of "Instructions for code acquisition").

The comparison between Figures 4 and 5 shows that the heave mode is the only mode that has not been affected by the change of the mooring system. When the platform has a surge or sway displacement, the mooring restoring load exerting on the platform increases more quickly if it is moored by the SPM system rather than the MPM. On the contrary, the roll-roll stiffness and the pitch-pitch stiffness of the SPM system are less than those of the MPM system. In particular, the yaw-yaw stiffness decreases to zero in the SPM layout. It means that the platform can rotate freely with respect to the $z$-axis no matter how big the yaw displacement. In addition, the platform displacements in roll and pitch lead to surge and sway restoring as well, which are much larger than those of the MPM system.

(a)

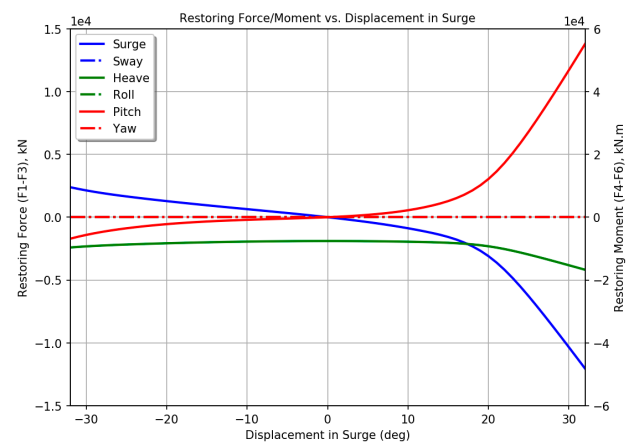

(c)

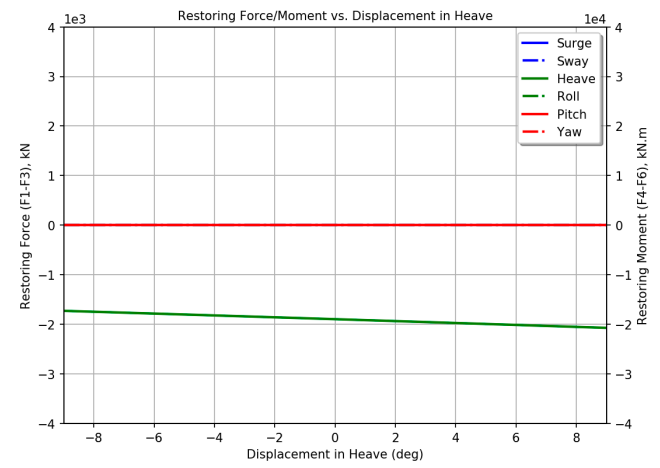

(e)

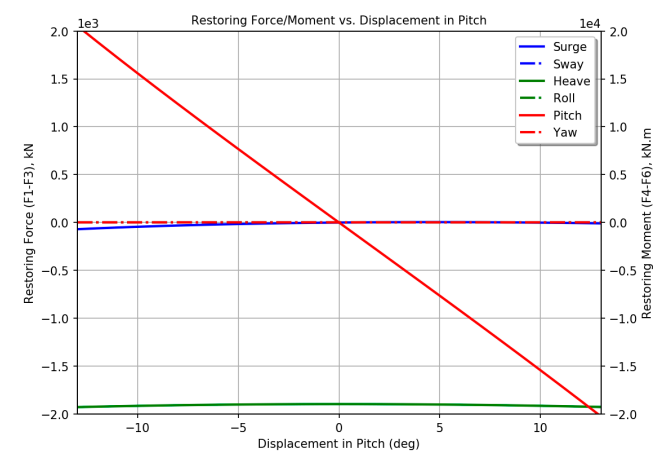

(b)

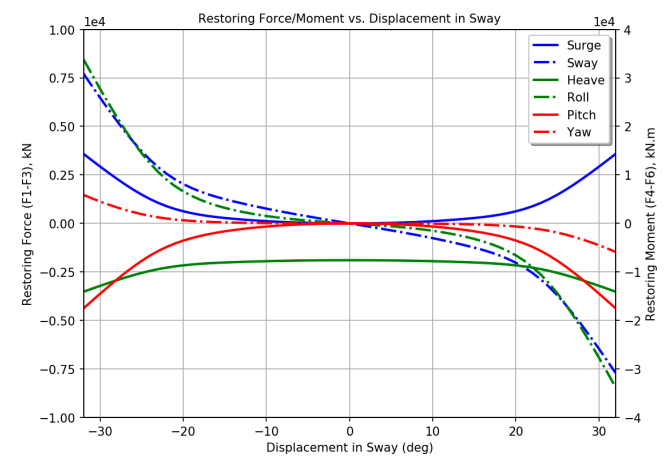

(d)

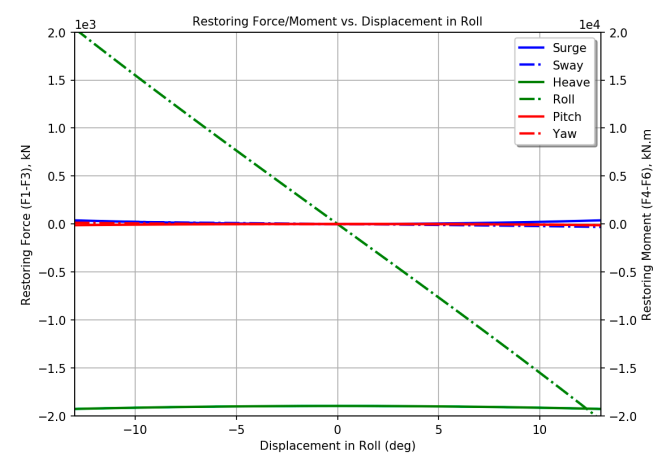

(f)

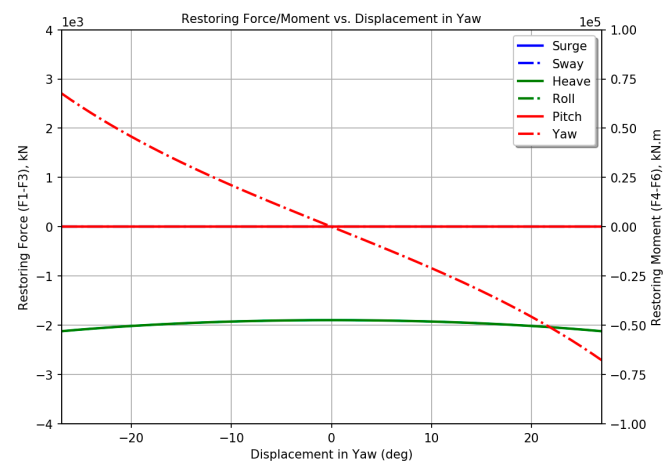

Figure 4. Load-displacement relationships for the DeepCwind MPM system (recalculated based on the descriptions in Section 5.3 of [27]), restoring force/moment against displacement: (a) in surge; (b) in sway; (c) in heave; (d) in roll; (e) in pitch and (f) in yaw. 
(a)

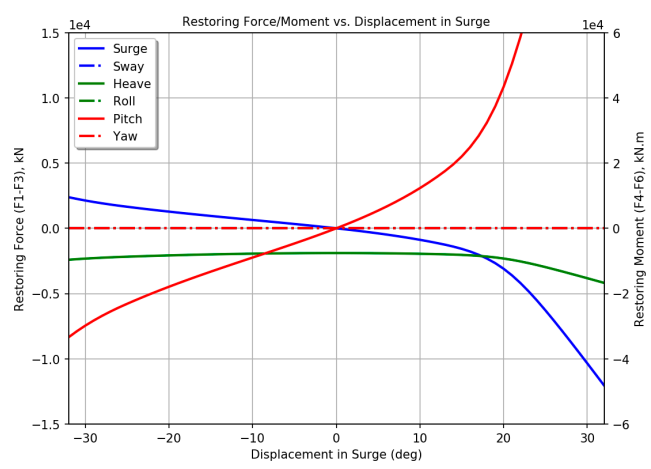

(c)

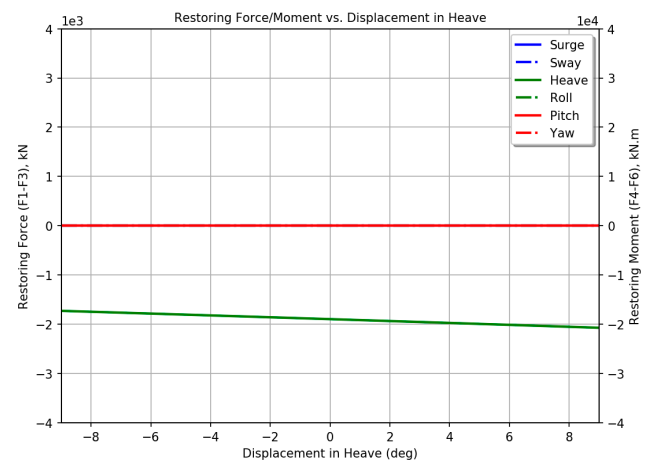

(e)

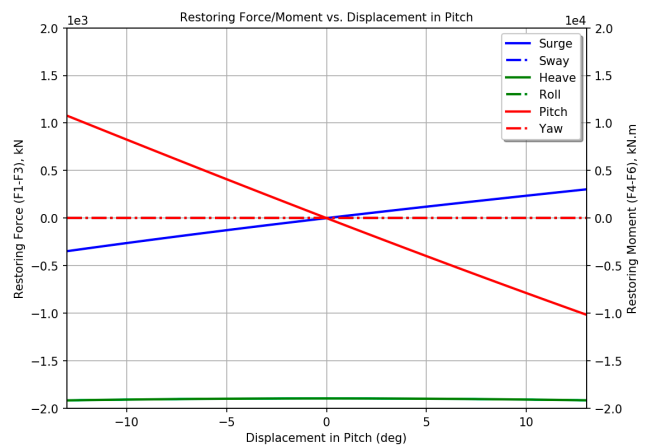

(b)

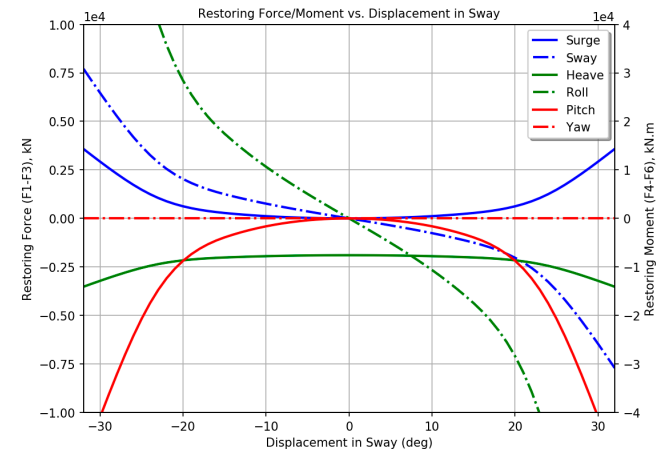

(d)
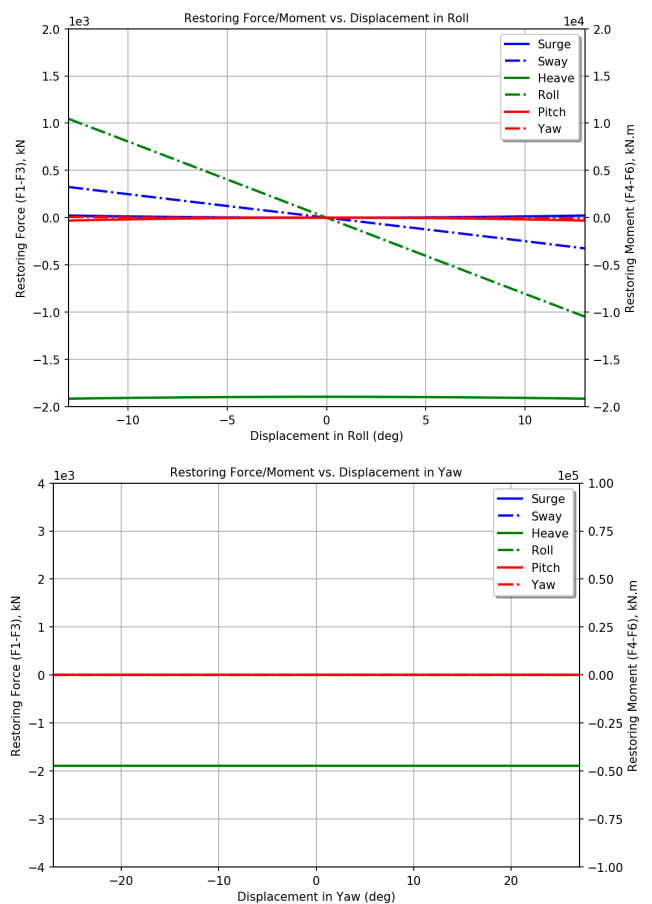

Figure 5. Load-displacement relationships for the DeepCwind SPM system, restoring force/moment against displacement: (a) in surge; (b) in sway; (c) in heave; (d) in roll; (e) in pitch and (f) in yaw.

The python wrapper also possesses a built-in feature that it can predict the linearized mooring stiffness matrix of a floating system. If the mooring compliance were assumed linear and the mooring inertia and damping were ignored [27], the total load upon the support platform from all-lines contribution would be

$$
F_{i}^{\text {Lines }}(q)=F_{i}^{\text {Lines }, 0}-C_{i j}^{\text {Lines }} q_{j},
$$

where $F_{i}^{\text {Lines, } 0}$ represents the pre-tension at the fairleads from the weight of the mooring lines not resting on the seafloor in water, $C_{i j}^{L i n e s}$ represents the $(i, j)$ component of the restoring matrix, and $q_{j}$ is the $j$ th platform DOF. It is calculated from the FAST still-water simulation that $F_{i}^{\text {Lines, } 0}$ remains the same with that in Equations (5)-(14) of Reference [27]. However, via the calculation by the python wrapper linking with the MAP++ DLL, the linearized mooring stiffness matrix in the undisplaced position is found to be 


$$
C_{i j}^{\text {Lines }}=\left[\begin{array}{cccccc}
7.07 e 4 \mathrm{~N} / \mathrm{m} & 0 & 0 & 0 & -1.41 e 6 \mathrm{~N} / \mathrm{rad} & 0 \\
0 & 7.07 e 4 \mathrm{~N} / \mathrm{m} & 0 & 1.41 e 6 \mathrm{~N} / \mathrm{rad} & 0 & 0 \\
0 & 0 & 1.91 e 4 \mathrm{~N} / \mathrm{m} & 0 & 0 & 0 \\
0 & 1.41 e 6 \mathrm{Nm} / \mathrm{m} & 0 & 6.62 e 7 \mathrm{Nm} / \mathrm{rad} & 0 & 0 \\
-1.41 e 6 \mathrm{Nm} / \mathrm{m} & 0 & 0 & 0 & 6.62 e 7 \mathrm{Nm} / \mathrm{rad} & 0 \\
0 & 0 & 0 & 0 & 0 & 0
\end{array}\right] .
$$

From the comparison between Equation (6) with Equations (5-15) of Reference [27], it is found that, by applying the SPM system instead of the MPM, the changes take place at the rotational-rotational diagonal terms and the surge-pitch, sway-roll, pitch-surge and roll-sway crossing terms.

\subsection{RAOs in Waves with and without Wind}

RAOs are calculated based on time-domain simulations with white-noise wave excitations, as described in Table 8. The load cases considered here correspond to LCs 2.6 and 3.7 in the OC4, Phase II Project. Four sets of computations are carried out using banded white-noise spectrums with four different seed numbers. The simulations are run for one hour but discarding the first 200 seconds which may include some unsteady transient effects. Auto-spectral density of the input (wave elevation) and cross-spectral density between the input and output (system responses) are computed based on Fast Fourier Transform of the averaged time-domain signals from the four sets of FAST simulations. The ratio of the cross-spectral density and the auto-spectral density gives rise to the RAO [36] which is also named as the frequency-response function

$$
R A O(\omega)=\frac{S_{x y}(\omega)}{S_{x x}(\omega)}
$$

where the numerator and the denominator on the right-hand side of Equation (7) correspond to the cross-spectral and auto-spectral densities of the input and output signals.

Table 8. Properties of load cases in the RAOs (Response Amplitude Operators) computation; PSD:

\begin{tabular}{|c|c|c|c|c|c|}
\hline $\begin{array}{l}\text { Load } \\
\text { Case }\end{array}$ & Description & $\begin{array}{l}\text { Enabled } \\
\text { DOFs }\end{array}$ & $\begin{array}{l}\text { Simulation } \\
\text { Length }\end{array}$ & Wind Condition & Wave Condition \\
\hline V & $\begin{array}{l}\text { RAO } \\
\text { estimation, } \\
\text { no wind }\end{array}$ & $\begin{array}{l}\text { Support } \\
\text { structure }\end{array}$ & $60 \mathrm{~min}$ & No wind & $\begin{array}{c}\text { Banded white noise, } \\
\mathrm{PSD}=1 \mathrm{~m}^{2} / \mathrm{Hz} \text { for } \\
0.05-0.25 \mathrm{~Hz}\end{array}$ \\
\hline VI & $\begin{array}{l}\text { RAO } \\
\text { estimation, } \\
\text { with wind }\end{array}$ & $\begin{array}{l}\text { Support } \\
\text { structure }\end{array}$ & $60 \mathrm{~min}$ & $\begin{array}{c}\text { Steady, uniform, } \\
\text { no shear: } V_{\text {hub }}=8 \mathrm{~m} / \mathrm{s}\end{array}$ & $\begin{array}{c}\text { Banded white noise, } \\
\mathrm{PSD}=1 \mathrm{~m}^{2} / \mathrm{Hz} \text { for } \\
0.05-0.25 \mathrm{~Hz}\end{array}$ \\
\hline
\end{tabular}
Power Spectral Density.

As seen in Figure 6, since the waves are excited only within the frequency band between 0.05 and $0.25 \mathrm{~Hz}$, analysis results outside the band are meaningless hence all RAOs are only shown within the excited band [37]. Figures 7 and 8 show that in general the wind has little effect on the surge, heave and pitch platform motions, except the lower-frequency region of the pitch RAO, where the existence of wind increases the responses of both the MPM and the SPM systems. The wind influences more significantly on the sway, roll and yaw platform motions, especially the response of yaw in the SPM system. This is easy to understand because there exists no yaw stiffness in the SPM system and the platform can freely change its yaw displacement in the presence of wind. Comparison between Figures 7 and 8 show that generally the RAOs computed by MoorDyn are slightly smaller than those by MAP++, since MoorDyn includes line damping and drag. 


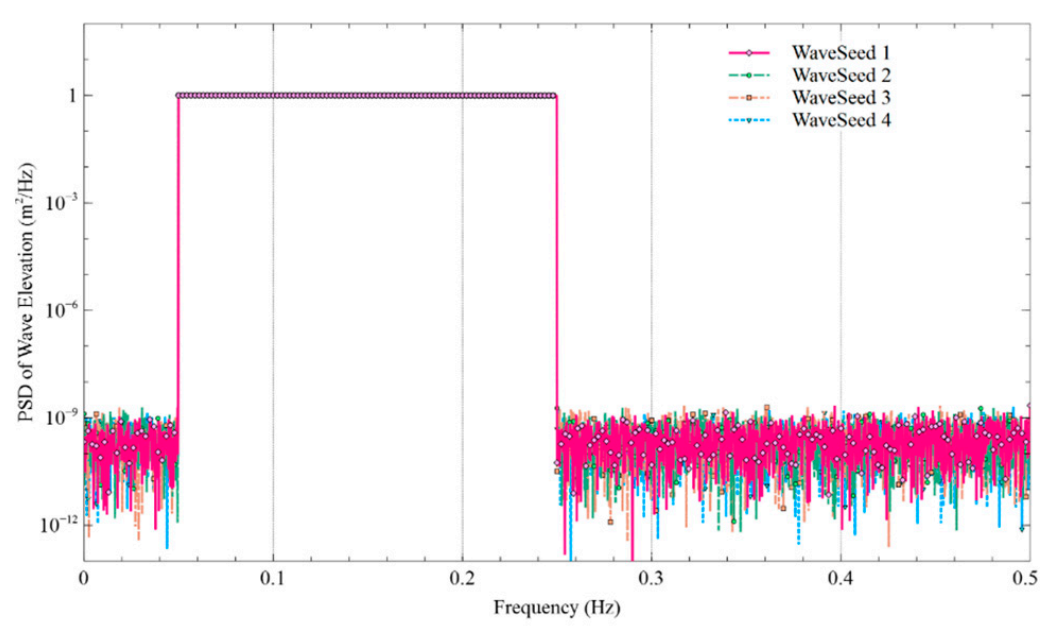

Figure 6. Power spectral density of the incident wave elevations with four different wave seeds for the white-noise spectrum.

(a)

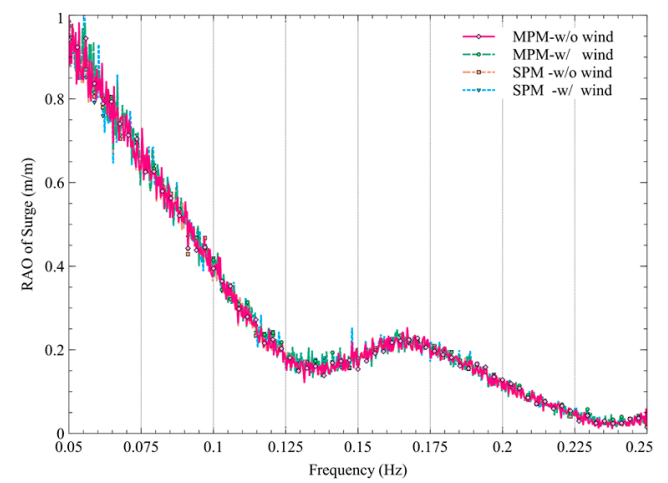

(c)

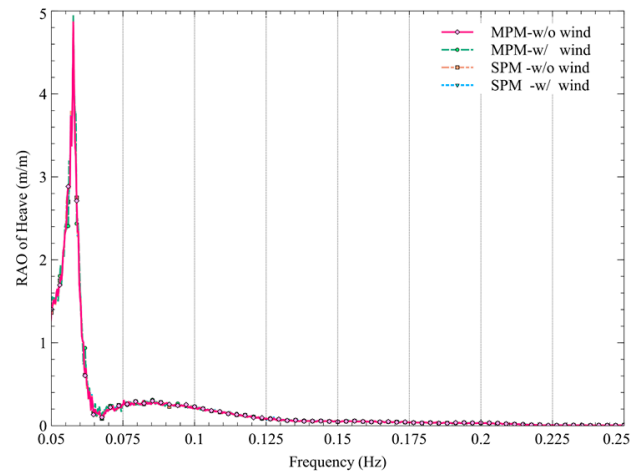

(e)

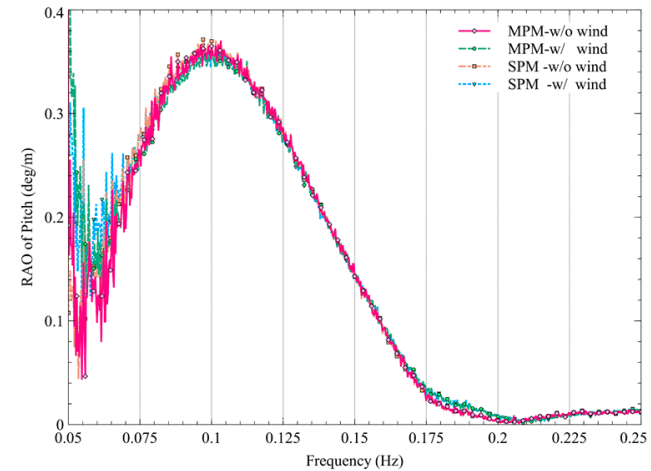

(b)

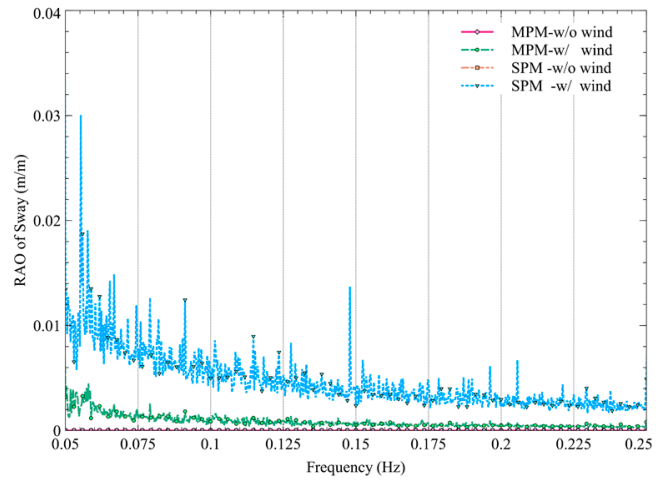

(d)

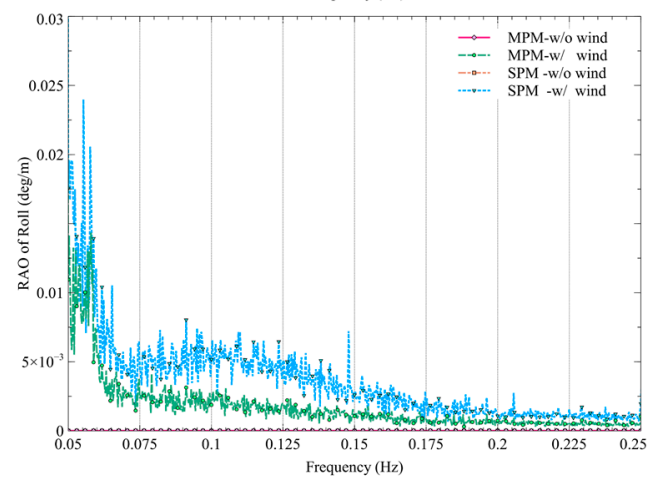

(f)

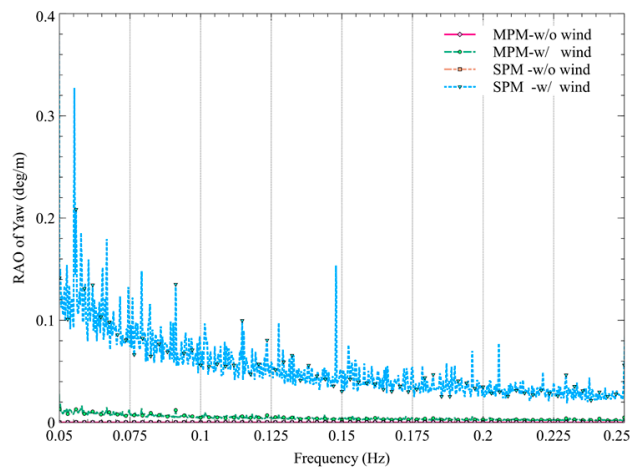

Figure 7. Platform motion RAOs computed by MAP++ for the DeepCwind MPM and SPM systems with and without wind: (a) in surge; (b) in sway; (c) in heave; (d) in roll; (e) in pitch and (f) in yaw. 
(a)

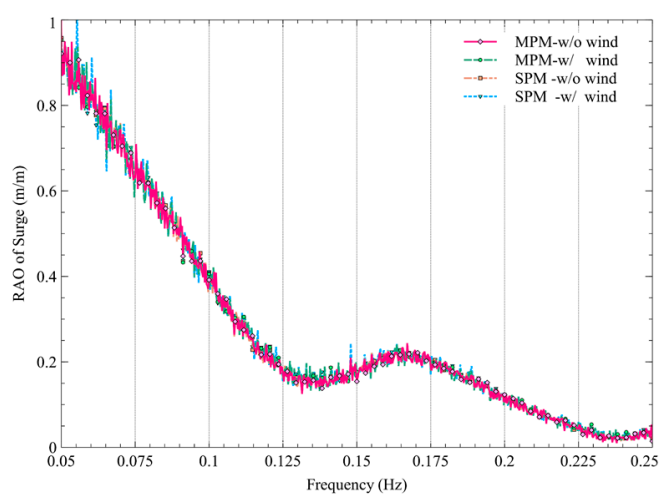

(c)

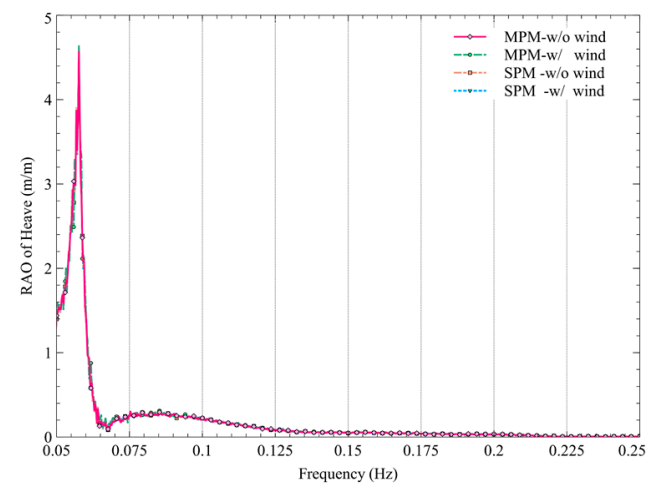

(e)

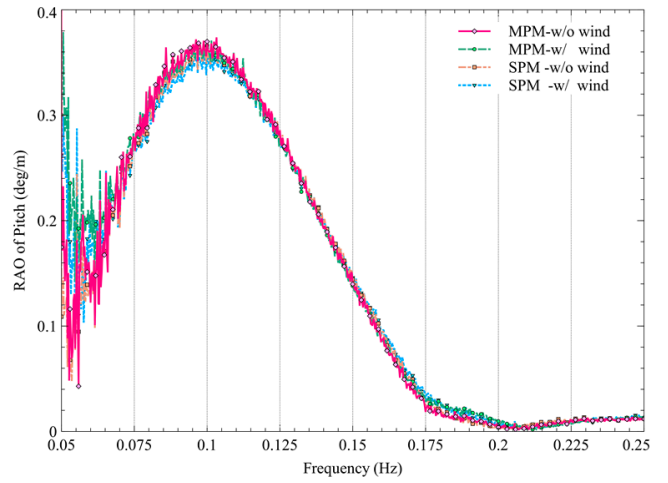

(b)

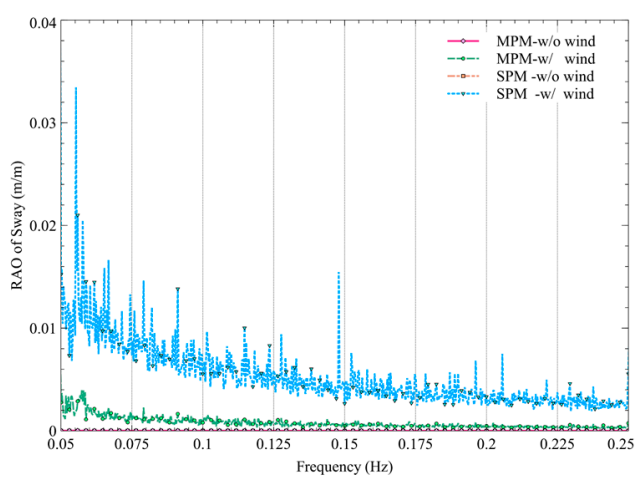

(d)

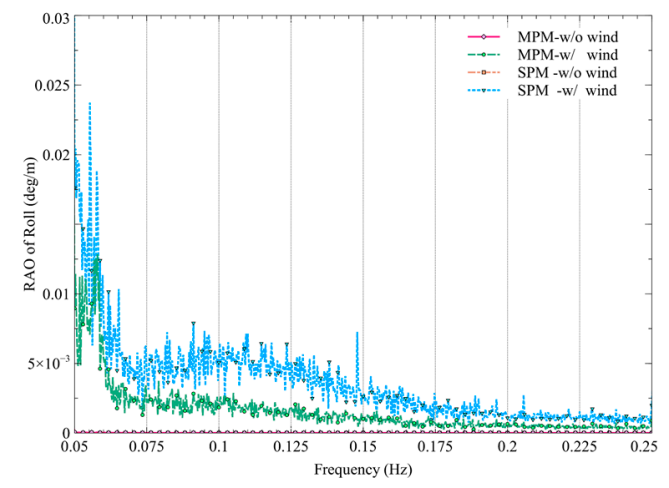

$(\mathbf{f})$

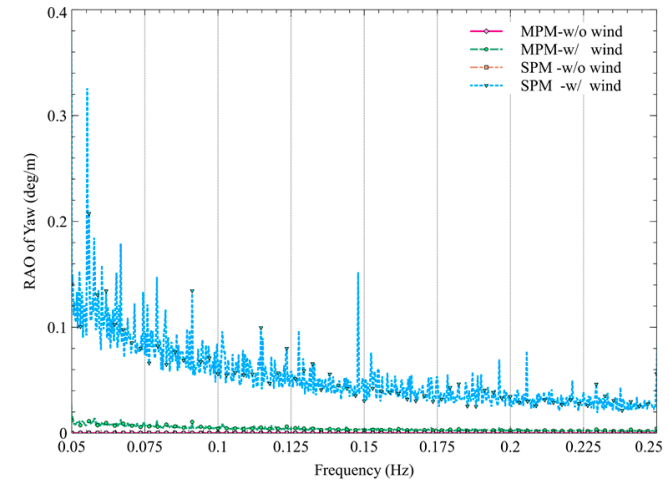

Figure 8. Platform motion RAOs computed by MoorDyn for the DeepCwind MPM and SPM systems with and without wind: (a) in surge; (b) in sway; (c) in heave; (d) in roll; (e) in pitch and (f) in yaw.

\subsection{Weathervane Test in Steady Wind}

An important application of the SPM system for floating offshore wind turbine is the self-aligned yaw control ability, which can reduce the cost of nacelle yaw system. Therefore, a weathervane test of the SPM turbine is performed using FAST in the steady-wind and still-water condition. The wind comes with a rated wind speed $11.4 \mathrm{~m} / \mathrm{s}$ of the NREL $5 \mathrm{MW}$ baseline turbine, from various directions ranging from -20 degrees to 20 degrees, step by 5 degrees. Simulations are not performed with a too-large wind direction angle because of the limitation in the FAST that it adopts a small-angle approximation for the platform rotations to avoid the sequence of rotation (Equation 2-2 in Reference [21]). The limit threshold angle is 20 degrees exceeding which the FAST simulations will loss considerable accuracy. The wind inflow directions are therefore set within this range to assure the enough accuracy of computation.

In the simulations, the input parameter of YawDOF in the ElastoDyn is set to be false for the SPM turbine so that the nacelle yaw is always fixed. As shown by Figure 9, the platform does rotate in accordance with the wind inflow direction. Nevertheless, there are three important points worth to be noted. Above all, the platform does not rotate to an angle exactly the same with the wind direction, e.g., when the wind comes from 20 degrees, the ultimate platform weathervane yaw angle is 10 degrees, 
having a twice difference. Secondly, the ultimate platform weathervane angles (after the platform reaching a steady state) are not equalized between two image wind directions with respect to the $x-z$ plane, e.g., for the wind directions of -15 and 15 degrees, the platform weathervane angles are finally -12.58 and 6.39 degrees, respectively. Furthermore, the standard deviations for the time-histories of two image wind directions also show a quite obvious asymmetry. This asymmetry of motion response is basically attributed to the aerodynamic asymmetry of the rotor properties. Unless the airfoils are symmetric (having zero camber), the aerodynamic twist angles are zero, the blade-pitch angles are 90 degrees, and the rotor is not rotating, the rotor will be aerodynamically asymmetric. In addition, the blade structural twist could also induce asymmetry in the rotor.

The phenomena can be understood as well in another way, which are explained in detail as below. Firstly, due to existence of the wind shear distribution, the rotor has a higher side force at its upper part and a lower side force at its lower part. The net side force induces a yaw moment with respect to the tower center, as shown in Figure 10. Secondly, because of the shaft tilt, the $V_{y}$ component of the relative wind speed to the blade is smaller when the blade is going upward (induction factor $a$ is larger) and larger when the blade is going downward (induction factor $a$ is smaller), leading to the imbalance of the rotor thrust force between the left and the right side of the rotor and finally inducing a yaw moment, as shown in Figure 11. Last but not least, due to the presence of blade cone angle, the blade with a larger projection area to the wind experiences a higher thrust force than the one with a smaller projection area, as shown in Figure 12. The deviation of the thrust force causes a yaw moment as well with respect to the tower center. A net summation of all the above three moments (there may be other more) leads to the wind-induced weathervane of the platform yaw motion.

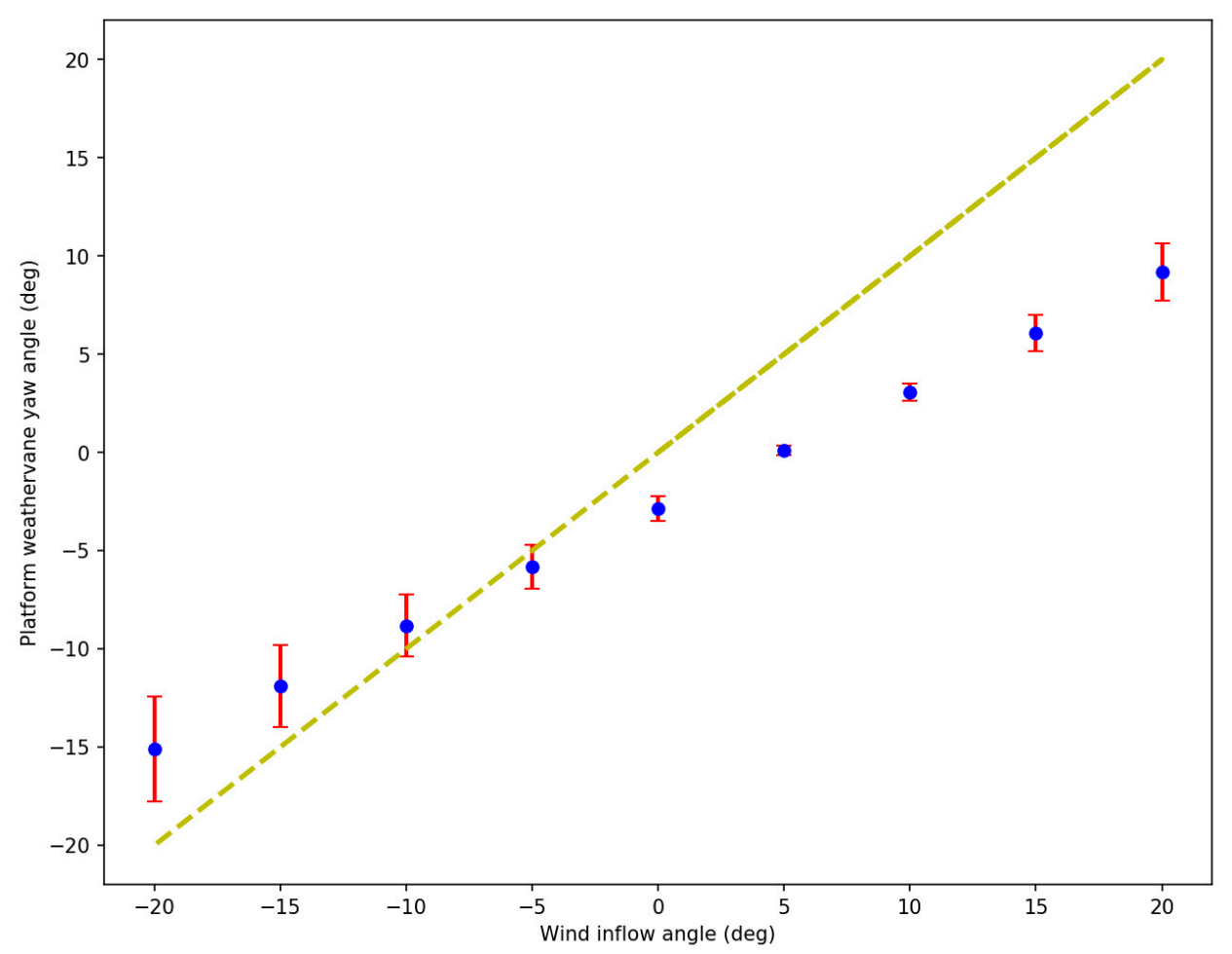

Figure 9. Platform weathervane yaw angle against wind inflow direction (results calculated by MAP++ overlapped those by MoorDyn hence only the latter are shown): points and bars stand for mean positions and standard deviations of the platform yaw displacements, respectively. The difference between each point and the counter-part value on the dash line indicates the platform weathervane misalignment. 


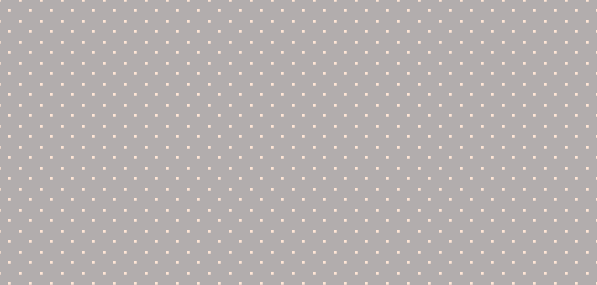

(a)

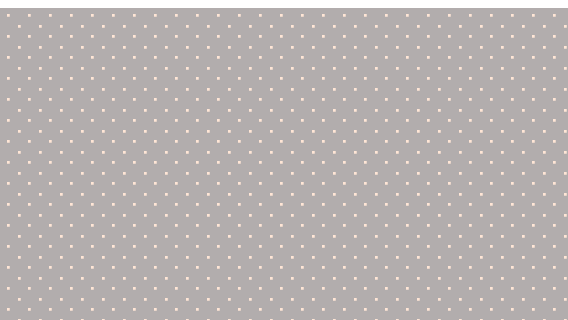

(b)

Figure 10. Yaw moment attributed to the wind shear: (a) front view of rotor; (b) top view of wind turbine.

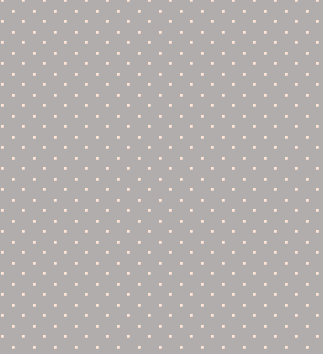

(a)

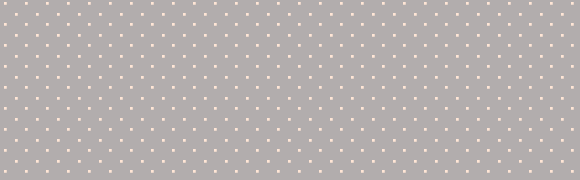

(b)

Figure 11. Yaw moment attributed to the shaft tilt: (a) side view of wind turbine; (b) velocity component analysis at the rotor plane.

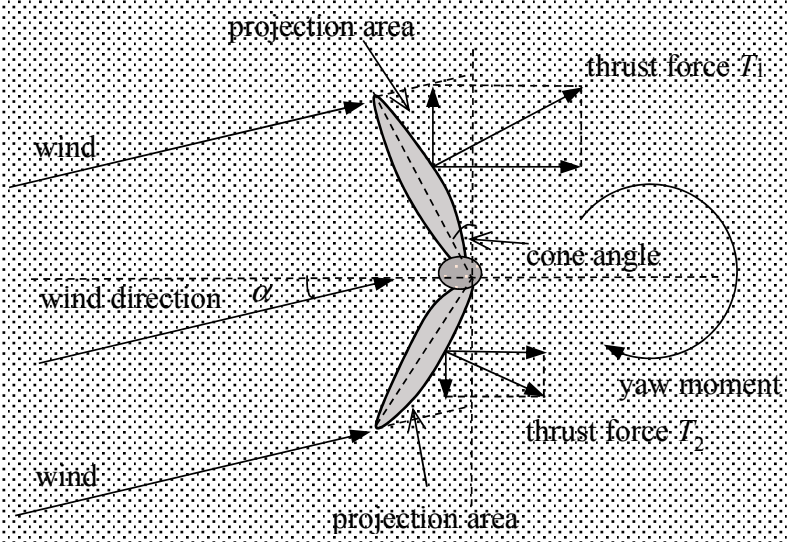

Figure 12. Yaw moment attributed to the cone angle of the blades.

\section{Conclusions}

In this study, a numerical analysis has been done on finding the response characteristics of a semisubmersible FWT when it is moored by an SPM system, based on the well-proven open-source software FAST. An extensive discussion has been made and useful conclusions have been obtained, which can be summarized into the following aspects:

1. The free-decay test shows that SPM layout elongates the natural periods of the wind turbine in rotational modes, but this is not the case for the translational natural periods.

2. Further analysis of the force-displacement relationship based on the Python wrapper of MAP++ library shows that the diagonal rotational mooring restoring terms decrease due to the SPM layout, and the crossing stiffness terms are also changed.

3. RAO comparisons elucidate that the presence of wind significantly influences the sway, roll and yaw motions of the wind turbine moored by the SPM layout, in comparison to the one moored by the MPM layout. 
4. The weathervane test shows that an asymmetry of the free-yaw motion response exists when the FWT is moored by an SPM system, attributed to the aerodynamic asymmetry of the rotor properties.

These findings are valuable to the design and application of the SPM technology in moored FWTs.

Author Contributions: Conceptualization, Y.L. and S.Y.; methodology, Y.L.; software, Y.L.; validation, Y.L., H.Y. and A.T.; formal analysis, Y.L., S.Y., H.Y., A.T., G.H. and S.Y.; investigation, Y.L.; writing-original draft preparation, Y.L.; writing-review and editing, H.Y., A.T., G.H. and S.Y.; supervision, S.Y.

Funding: A small part of the APC (60 CHF) was funded by the Kyushu University Platform of Inter/Transdisciplinary Energy Research (Q-PIT) Support Program for Young Researchers (Grant Number 18112).

Acknowledgments: The first author gratefully thanks the financial support from the Q-PIT Support Program for Young Researchers (Grant Number 18112), the Overseas Collaborative Research Program (Grant Number PJT-8) of the Japan Society of Naval Architects and Ocean Engineers (JASNAOE) and Grant-in-Aid for Early-Career Scientists (JSPS KAKENHI Grant Number JP18K13939) for his research. The authors are grateful to the guidance and help from Dr. Jason Jonkman of NREL and Dr. Marco Masciola of Siemens Gamesa during the course of this study.

Conflicts of Interest: No potential conflict of interest was reported by the authors.

Instructions for code acquisition: The Python subroutine (to be run together with the MAP++ solver) for analysis of the force-displacement relationship of an arbitrary mooring system, developed in the present study, is freely available on contacting the first author.

\section{Nomenclature}

$\begin{array}{ll}\text { CAE } & \text { Computer Aided Engineering } \\ \text { DLL } & \text { Dynamic Link Library } \\ \text { DOF } & \text { Degree of Freedom } \\ \text { FAST } & \text { Fatigue, Aerodynamics, Structures, and Turbulence } \\ \text { FEA } & \text { Finite Element Analysis } \\ \text { FWT } & \text { Floating Wind Turbine } \\ \text { FPSO } & \text { Floating Production, Storage and Offloading unit } \\ \text { LC } & \text { Load Case } \\ \text { MAP++ } & \text { Mooring Analysis Program } \\ \text { MPM } & \text { Multiple-Point Mooring } \\ \text { MSQS } & \text { Multi-Segmented, Quasi-Static } \\ \text { NREL } & \text { National Renewable Energy Laboratory } \\ \text { OC4 } & \text { Offshore Code Comparison Collaboration Continuation } \\ \text { OWE } & \text { Offshore Wind Energy } \\ \text { PSD } & \text { Power Spectral Density } \\ \text { RAO } & \text { Response Amplitude Operator } \\ \text { SPM } & \text { Single-Point Mooring } \\ \text { TLS } & \text { Tension Leg Spar } \\ \text { WEC } & \text { Wave Energy Converter }\end{array}$

\section{References}

1. Roddier, D.; Cermelli, C.; Aubault, A.; Weinstein, A. WindFloat: A floating foundation for offshore wind turbines. J. Renew. Sustain. Energy 2010, 2, 033104. [CrossRef]

2. Skaare, B.; Nielsen, F.G.; Hanson, T.D.; Yttervik, R.; Havmøller, O.; Rekdal, A. Analysis of measurements and simulations from the Hywind Demo floating wind turbine. Wind Energy 2015, 18, 1105-1122. [CrossRef]

3. Viselli, A.M.; Goupee, A.J.; Dagher, H.J. Model test of a 1:8-scale floating wind turbine offshore in the gulf of maine. J. Offshore Mech. Arctic Eng. 2015, 137, 041901. [CrossRef]

4. Liu, Y.; Li, S.; Yi, Q.; Chen, D. Developments in semi-submersible floating foundations supporting wind turbines: A comprehensive review. Renew. Sustain. Energy Rev. 2016, 60, 433-449. [CrossRef] 
5. Iijima, K.; Kawai, M.; Nihei, Y.; Murai, M.; Ikoma, T. Conceptual design of a single-point-moored FOWT and tank test for its motion characteristics. In Proceedings of the ASME 32nd International Conference on Ocean, Offshore and Arctic Engineering, Nantes, France, 9-14 June 2013; ASME: New York, NY, USA, 2013.

6. Koh, J.H.; Ng, E.Y.K.; Robertson, A.; Jonkman, J.; Driscoll, F. Validation of a FAST Model of the SWAY Prototype Floating Wind Turbine; (No. NREL/TP-5000-61744); National Renewable Energy Lab. (NREL): Golden, CO, USA, 2016.

7. Nihei, Y.; Matsuda, Y.; Kitamura, S.; Takaiwa, K.; Kanda, N. Research and development about the mechanisms of a single point mooring system for offshore wind turbines. Ocean Eng. 2018, 147, 431-446. [CrossRef]

8. Wang, Y.; Zou, C.; Ding, F.; Dou, X.; Ma, Y.; Liu, Y. Structural reliability based dynamic positioning of turret-moored FPSOs in extreme seas. Math. Probl. Eng. 2014, 2014, 302481. [CrossRef]

9. Li, B.; Huang, W.; Araujo, R.; Boulland, J.; Chen, X. Gangway motion evaluation of an accommodation vessel operating along a turret moored FPSO. In Proceedings of the Twenty-fifth International Ocean and Polar Engineering, Kona, HI, USA, 21-26 June 2015; ISOPE: Mountain View, CA, USA, 2015.

10. Wu, W.; Wang, Y.; Tang, D.; Yue, Q.; Du, Y.; Fan, Z.; Lin, Y.; Zhang, Y. Design, implementation and analysis of full coupled monitoring system of FPSO with soft yoke mooring system. Ocean Eng. 2016, 113, $255-263$. [CrossRef]

11. Islam, A.S.; Soeb, M.R.; Jumaat, M.Z.B. Floating spar platform as an ultra-deepwater structure in oil and gas exploration. Ships Offshore Struct. 2017, 12, 923-936. [CrossRef]

12. Cao, Y.; Yu, X.; Xiang, G.; Ruan, W.; Lu, P. On critical parameters of squall associated with the mooring design of a turret-moored FPSO. Ships Offshore Struct. 2018, 13((sup1)), 182-190. [CrossRef]

13. Sanchez-Mondragon, J.; Vázquez-Hernández, A.O.; Cho, S.K.; Sung, H.G. Motion behavior in a turret-moored FPSO caused by piston mode effects in moonpool. Ocean Eng. 2017, 140, 222-232. [CrossRef]

14. Xiao, L.; Tao, L.; Yang, J.; Li, X. An experimental investigation on wave runup along the broadside of a single point moored FPSO exposed to oblique waves. Ocean Eng. 2014, 88, 81-90. [CrossRef]

15. Thomsen, J.B.; Kofoed, J.P.; Delaney, M.; Banfield, S. Initial Assessment of Mooring Solutions for Floating Wave Energy Converters. In Proceedings of the 26th International Ocean and Polar Engineering Conference, Rhodes, Greece, 26 June-2 July 2016; ISOPE: Mountain View, CA, USA, 2016.

16. Thomsen, J.B.; Ferri, F.; Kofoed, J.P.; Black, K. Cost Optimization of Mooring Solutions for Large Floating Wave Energy Converters. Energies 2018, 11, 159. [CrossRef]

17. Jonkman, J.M.; Buhl, M.L., Jr. FAST User's Guide; (No. NREL/TP-500-38230); National Renewable Energy Laboratory (NREL): Golden, CO, USA, 2005.

18. Jonkman, J.M. The New Modularization Framework for the FAST Wind Turbine CASE Tool. In Proceedings of the 32nd ASME Wind Energy Symposium, Grapevine, TX, USA, 7-10 January 2013.

19. Sprague, M.A.; Jonkman, J.M.; Jonkman, B. FAST modular framework for wind turbine simulation: New algorithms and numerical examples. In Proceedings of the 33rd Wind Energy Symposium, Kissimmee, FL, USA, 5-9 January 2015.

20. Kane, T.R.; Levinson, D.A. Dynamics: Theory and Applications; McGraw Hill: New York, NY, USA, 2007; Volume 3, ISBN 0070378460.

21. Jonkman, J.M. Dynamics Modeling and Loads Analysis of an Offshore Floating Wind Turbine; University of Colorado at Boulder: Boulder, CO, USA, 2007; Volume 3, ISBN 0070378460.

22. Jonkman, J.M. Dynamics of offshore floating wind turbines-Model development and verification. Wind Energy 2009, 12, 459-492. [CrossRef]

23. Hall, M.; Goupee, A. Validation of a lumped-mass mooring line model with DeepCwind semisubmersible model test data. Ocean Eng. 2015, 104, 590-603. [CrossRef]

24. Thomsen, J.B.; Ferri, F.; Kofoed, J.P. Experimental testing of moorings for large floating wave energy converters. In Proceedings of the International Conference on Renewable Energies Offshore, Lisbon, Portugal, 24-26 October 2016; CRC Press: Boca Raton, FL, USA, 2016.

25. Hall, M.; Buckham, B.; Crawford, C. Evaluating the importance of mooring line model fidelity in floating offshore wind turbine simulations. Wind Energy 2014, 17, 1835-1853. [CrossRef]

26. Wendt, F.F.; Andersen, M.T.; Robertson, A.N.; Jonkman, J.M. Verification and validation of the new dynamic mooring modules available in FAST v8. In Proceedings of the 26th International Ocean and Polar Engineering Conference, Rhodes, Greece, 6 June-2 July 2016; ISOPE: Mountain View, CA, USA, 2016. 
27. Robertson, A.; Jonkman, J.M.; Masciola, M.; Song, H.; Goupee, A.; Coulling, A.; Luan, C. Definition of the Semisubmersible Floating System for Phase II of OC4; National Renewable Energy Laboratory (NREL): Golden, CO, USA, 2014.

28. Goupee, A.; Koo, B.; Lambrakos, K.; Kimball, R. Model tests for three floating wind turbine concepts. In Proceedings of the Offshore Technology Conference, Houston, TX, USA, 30 April-3 May 2012.

29. Coulling, A.; Goupee, A.J.; Robertson, A.N.; Jonkman, J.M.; Dagher, H.J. Validation of a FAST semi-submersible floating wind turbine numerical model with DeepCwind test data. J. Renew. Sustain. Energy 2013, 5, 023116. [CrossRef]

30. Benitz, M.A.; Schmidt, D.P.; Lackner, M.A.; Stewart, G.M.; Jonkman, J.M.; Robertson, A. Validation of hydrodynamic load models using CFD for the OC4-DeepCwind semisubmersible. In Proceedings of the ASME 2015 34th International Conference on Ocean, Offshore and Arctic Engineering, St. John's, NL, Canada, 31 May-5 June 2015; ASME: New York, NY, USA, 2015.

31. Jonkman, J.M.; Robertson, A.; Hayman, G.J. HydroDyn User's Guide and Theory Manual; National Renewable Energy Laboratory: Golden, CO, USA, 2014.

32. Liu, Y.; Hu, C.; Sueyoshi, M.; Iwashita, H.; Kashiwagi, M. Motion response prediction by hybrid panel-stick models for a semi-submersible with bracings. J. Mar. Sci. Technol. 2016, 21, 742-757. [CrossRef]

33. Masciola, M. Instructional and Theory Guide to the Mooring Analysis Program. NREL. Available online: https://nwtc.nrel.gov/system/files/MAP_v0,87 (accessed on 3 August 2018).

34. Masciola, M.; Jonkman, J.; Robertson, A. Implementation of a multisegmented, quasi-static cable model. In Proceedings of the Twenty-third International Offshore and Polar Engineering Conference, Anchorage, AK, USA, 30 June-5 July 2013; ISOPE: Mountain View, CA, USA, 2013.

35. Jonkman, J.; Butterfield, S.; Musial, W.; Scott, G. Definition of a 5-MW Reference Wind Turbine for Offshore System Development; (No. NREL/TP-500-38060); National Renewable Energy Lab. (NREL): Golden, CO, USA, 2009.

36. Ramachandran, G.K.V.; Robertson, A.; Jonkman, J.M.; Masciola, M.D. Investigation of Response Amplitude Operators for Floating Offshore Wind Turbines. In Proceedings of the Twenty-third International Offshore and Polar Engineering, Anchorage, AK, USA, 30 June-5 July 2013; ISOPE: Mountain View, CA, USA, 2013.

37. Robertson, A.; Jonkman, J.; Vorpahl, F.; Popko, W.; Qvist, J.; Frøyd, L.; Chen, X.; Azcona, J.; Uzunoglu, E.; Soares, C.G.; et al. Offshore code comparison collaboration continuation within IEA wind task 30: Phase II results regarding a floating semisubmersible wind system. In Proceedings of the ASME 2014 33rd International Conference on Ocean, Offshore and Arctic Engineering, San Francisco, CA, USA, 8-13 June 2014; ASME: New York, NY, USA, 2014. 